\title{
1 NO Oxidation by Microporous Zeolites: Isolating \\ 2 the Impact of Pore Structure to Predict NO Conversion
}

4 Zhanquan Zhang ${ }^{a, b, c}$, John D. Atkinson ${ }^{b}$, Boqiong Jiang $^{d}$, Mark J Rood ${ }^{a, b^{*}}$, Zifeng Yan $^{a \dagger}$

5

${ }^{a}$ State Key Laboratory of Heavy Oil Processing, Key Laboratory of Catalysis CPNC, China University of Petroleum, Qingdao 266580, China

${ }^{\mathrm{b}}$ Department of Civil and Environmental Engineering, University of Illinois, 205 N. Mathews. Ave., IL 61801, USA

${ }^{\mathrm{c}}$ College of Mechanical and Electrical Engineering, China University of Petroleum, Qingdao 266580, China

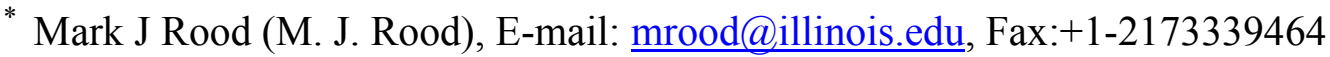

${ }^{\dagger}$ Zifeng Yan (Z. Yan), E-mail: zfyancat@upc.edu.cn, Fax: +86-53286981295 
Anthropogenic $\mathrm{NO}_{\mathrm{x}}$ emissions to the atmosphere from stationary sources continue to be of concern because of their adverse effects on public health and the environment. An alternative method to conventional selective catalytic reduction to reduce the amount of $\mathrm{NO}_{\mathrm{x}}$ emissions is oxidation of $\mathrm{NO}$ to more soluble $\mathrm{NO}_{2}$ upstream of an absorption device. Zeolites and activated carbon are effective NO oxidation catalysts, but their oxidation mechanisms are not fully understood. Here, zeolites were evaluated as NO oxidation catalysts experimentally and theoretically to identify preferred pore structures for $\mathrm{NO}$ conversion to $\mathrm{NO}_{2}$ and to show mechanistic similarities to activated carbon fiber-catalyzed NO oxidation. For the 17 zeolites tested here, steady-state NO conversion are not related to their chemical composition (i.e., $\mathrm{Si}$, $\mathrm{Al}$, or P). However, similar to carbonaceous catalysts, steady-state NO conversion mainly depend on the zeolite's physical properties, including the zeolite's cage size, pore width, and pore volume. Zeolites with maximum free sphere diameter $\left(D_{\max }\right)$ between $4.70 \AA$ and $6.45 \AA$, or zeolites with maximum included sphere diameter $\left(D_{i}\right)$ between $5.71 \AA$ and $7.37 \AA$, derived from experimental results, are most effective for $\mathrm{NO}$ oxidation to $\mathrm{NO}_{2}$ regardless of the zeolites' channel to cage ratio. A mechanism for NO oxidation proceeding through the

31 [ONOONO] transition state (TS) is described here, challenging the reported mechanism that adsorbed $\mathrm{C}^{*}-\mathrm{NO}_{3}$ species are the precursors of $\mathrm{NO}_{2}$ formation. Void spaces with dimensions similar to or slightly larger (i.e., $7 \AA$ width) than the size of the TS $(4.46 \AA \times 4.67 \AA \times 6.94$

$34 \AA$, derived from TS calculations) are the most effective spaces for NO oxidation due to strengthened van der Waals interaction between the confined TS and pore walls of the 
36 zeolite. Criteria for screening effective zeolites for NO oxidation are proposed based on

37 results for the 17 tested zeolites, and 82 of the 206 available zeolite codes are predicted to be

38 effective with high steady-state NO conversion. Consistent physical geometries of zeolite

39 pore sizes $\left(D_{i}=4.70 \AA-6.45 \AA\right.$ or $\left.D_{\max }=5.71 \AA-7.37 \AA\right)$, activated carbon fiber pore

40 widths (5 $\AA-7 \AA$ ) provide convincing evidence that such pore sizes are needed to provide

41 efficient steady-state NO conversion. These results may be extended to other categories of

42 microporous materials to choose the most appropriate material for catalytic NO conversion to

$43 \quad \mathrm{NO}_{2}$.

44 Keywords: NO oxidation; Catalysis; Zeolite; Activated carbon; Transition states

45

46

47

48

49

50 


\section{Introduction}

55 Anthropogenic nitrogen oxides $\left(\mathrm{NO}_{\mathrm{x}}\right.$, as $\mathrm{NO}$ and $\left.\mathrm{NO}_{2}\right)$, mainly emitted from stationary and

56 mobile combustion sources, deteriorate the environment and human health [1]. Acid rain,

57 stratospheric ozone depletion, photochemical smog, secondary particulate matter, and

58 respiratory diseases can all be at least partially attributed to $\mathrm{NO}_{\mathrm{x}}$ emissions [2, 3]. In China,

$59 \mathrm{NO}_{\mathrm{x}}$ emissions were $1.46 \times 10^{10} \mathrm{~kg} / \mathrm{yr}$ in 2010 , an increase of $14 \%$ from 2009 [4]. More

60 stringent legislation in China [5] and the USA necessitate the development and use of novel,

61 sustainable $\mathrm{NO}_{\mathrm{x}}$ control technologies.

62 Selective catalytic reduction with $\mathrm{V}_{2} \mathrm{O}_{5}-\mathrm{WO}_{3} / \mathrm{TiO}_{2}$ catalysts is the most mature and

63 common $\mathrm{NO}_{\mathrm{x}}$ control technology $[6,7]$. However, adsorption and catalytic oxidation with

64 liquid absorption (COLA) [8-10] are gaining interest because they operate at lower

65 temperatures $\left(<100{ }^{\circ} \mathrm{C}\right)$ and do not require additional reagents (e.g., $\left.\mathrm{NH}_{3}\right)$. COLA can also be

66 retrofitted into existing power plants. Such a $\mathrm{NO}_{\mathrm{x}}$ control strategy is especially valuable in

67 China because many existing boilers do not have sufficient space to accommodate new SCR

68 systems between economizers and heat exchangers [11].

69 Activated carbons [12-19], metal-free zeolites [20-24], and metal oxide impregnated or

70 ion-exchanged zeolites $[10,25,26]$ have been tested as $\mathrm{NO}_{\mathrm{x}}$ adsorbents and $\mathrm{NO}$ oxidation

71 catalysts. Microporous materials have low NO adsorption capacities $\left(<2 \mathrm{mg} \mathrm{g}^{-1}\right)$ compared to

$72 \mathrm{NO}_{2}\left(15-60 \mathrm{mg} \mathrm{g}^{-1}\right)$ [27], and $\mathrm{NO}$ is up to 20 times less soluble in water than $\mathrm{NO}_{2}$ [28-30].

73 Therefore, both adsorption and COLA processes rely on NO oxidation. Moderate to high

74 temperatures (e.g., $300{ }^{\circ} \mathrm{C}$ ) are required to enhance conversion for metal-catalyzed NO 
oxidation. However, NO oxidation via metal-free catalysis is more active at lower temperatures, with dependence on the physical (e.g., pore size distribution) and chemical (e.g., surface functional groups and acidity) properties of the catalyst [20-23, 31]. For this reason, this research focuses on identifying preferred physical and chemical catalyst properties for metal-free catalyzed NO oxidation.

The first example of zeolite catalyzed NO oxidation was shown by Richter et al. using

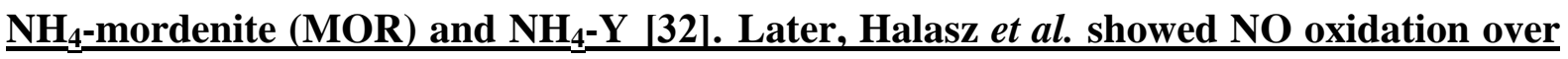
$\underline{\text { ZSM-5 with varying Si/Al molar ratios, proposing that bridging hydroxyls (Brønsted }}$ acids) are active sites for NO oxidation [33]. Liu et al. also used ZSM-5 for NO oxidation and reported that such conversion is independent of $\mathrm{Si} / \mathrm{Al}$ molar ratio. This is important $\underline{\text { because it allows for water resistant (high-silica) zeolites to oxidize NO to NO }} \underline{2}$. Kinetic analyses also showed that NO oxidation is second order $(2.03)$ in NO concentration

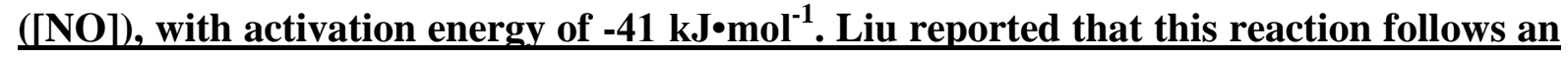
$\underline{\text { Eley-Rideal mechanism where } \mathrm{NO}_{2}} \underline{\text { is generated from reactions between gaseous } \mathrm{NO} \text { and }}$ $\underline{\text { adsorbed } \mathrm{NO}_{3}}[20-23]$. Na et al. investigated NO${ }_{x}$ adsorption using zeolites with select physical and chemical properties, showing that zeolite $13 \mathrm{X}$ has the highest $\mathrm{NO}_{\underline{x}}$ adsorption capacity among the investigated zeolites. However, relationships between adsorption capacity and the zeolites' properties were not established [24]. Lu et al. $\underline{\text { showed high NO}} \underline{x}_{\text {adsorption capacity for } \mathrm{Ca}-\beta\left(221 \mu \mathrm{mol} \mathrm{g}^{-1} \text { at } 40^{\circ} \mathrm{C}\right) \text {, possibly due to }}$ additional $\mathrm{CaO}$ adsorption sites and the three-dimensional framework (*BEA) of the $\beta$ zeolite catalyzing NO oxidation $[10]$. Currently, disagreements remain regarding the NO 
Loiland et al. [34], revealed that microporous void spaces provide catalytic sites that

stabilization. Loiland et al. also extended the scope of NO oxidation catalysts to include

microporous metal organic frameworks [34].

101 There are 206 unique zeolite frameworks and over 1400 zeolite crystals with varying geometric parameters and compositions [35]. Over 5.3 million zeolite structures are feasible, according to calculations in the Bronze database [36]. Hence, the preferred physical and chemical properties of zeolites for NO oxidation should be described more clearly to provide a framework for selecting zeolites that may have high catalytic activity for NO oxidation.

106 Activated carbon fiber-catalyzed NO conversion depends on the catalyst's physical

107 properties $[12,37,38]$. Similar studies are important to identify the preferred structure and

108 composition of zeolite catalysts. The mechanisms for activated carbon fiber-catalyzed and

109 zeolite-catalyzed NO oxidation should be compared to broaden the understanding of the NO

110 oxidation mechanism for microporous materials. If NO oxidation by zeolites relies on a

111 narrow range of micropore widths, then similar mechanisms might be applicable to a wider

112 range of materials.

113 This study experimentally investigates 17 zeolites with select physical structures and

114 chemical composition (i.e., $\mathrm{Si}, \mathrm{Al}, \mathrm{P}, \mathrm{Na}^{+}, \mathrm{NH}_{4}{ }^{+}, \mathrm{H}^{+}$and $\mathrm{Ca}^{2+}$ ) to identify the impact of the 115 catalysts' properties on steady-state and transient NO oxidation kinetics. Pore structures 116 (channels or cages) that are most active for NO oxidation are identified and the experimental 
117 results are extended to describe a reaction mechanism. TS [ONOONO] confinement [39] and

118 micropore (channels or cages) catalysis are proposed to explain differences in NO conversion.

119 Increasing the van der Waals interaction between the TS and pore walls of the zeolite by

120 adjusting the zeolite's void space dimensions and capacity results in notable differences

121 in NO conversion. These results are consistent with a previously described activated carbon

122 fiber-catalyzed mechanism and can be used to predict, in a more general manner, the properties

123 of porous catalysts for $\mathrm{NO}$ oxidation to $\mathrm{NO}_{2}$, and inspire further $\mathrm{NO}$ oxidation investigations

124 for other microporous materials.

125 2. Methods

126

\subsection{NO Oxidation Apparatus}

127 The NO oxidation reactor is described in detail elsewhere [12, 38], but is briefly described 128 here for clarity. Air (99.9995\%), nitrogen (99.999\%), and certified $1000 \mathrm{ppm}_{\mathrm{v}} \mathrm{NO}$ in $\mathrm{N}_{2}$ were 129 used to generate the gas streams. Mass flow controllers controlled the individual gas flow rates

130 resulting in the specified $[\mathrm{NO}],\left[\mathrm{O}_{2}\right]$, and total gas flow rate entering the reactor. Temperatures

$131\left(25{ }^{\circ} \mathrm{C} \pm 0.4{ }^{\circ} \mathrm{C}\right.$ or $\left.50{ }^{\circ} \mathrm{C} \pm 0.4{ }^{\circ} \mathrm{C}\right)$ were maintained in an open water bath. NO oxidation was

132 performed in a stainless steel, fixed-bed reactor packed with $0.25 \mathrm{~g}$ of dry zeolite (40-60 mesh,

133 Table 1). Unless otherwise noted, the inlet gas stream consisted of $400 \mathrm{ppm}_{\mathrm{v}} \mathrm{NO}, 10 \mathrm{vol} \% \mathrm{O}_{2}$,

134 and balance $\mathrm{N}_{2}$. Total inlet flow rate was 0.1 standard liters per minute (SLPM at $0{ }^{\circ} \mathrm{C}$ and 1

$135 \mathrm{~atm})$. A by-pass line to the downstream $\mathrm{NO}_{\mathrm{x}}$ detector was used to ensure a stable $\left[\mathrm{NO}_{\mathrm{x}}\right]$. After

136 tests, the bypass line was again used to confirm negligible changes in the inlet $[\mathrm{NO}](<0.5 \%$

137 change). $\left[\mathrm{NO}_{\mathrm{x}} \_\right.$was continuously measured with a NO-NO${ }_{2}=\underline{N O}_{\mathrm{x}}$ analyzer (Thermo 
139 oxidation was minimal $\left(1.6 \%\right.$ at $\left.50{ }^{\circ} \mathbf{C}\right)$. Each test was operated for $\geqq 20 \mathrm{~h}$ to achieve

140 steady-state outlet $[\mathrm{NO}]$ and $\left[\mathrm{NO}_{2}\right]\left(\right.$ change $\left.<1 \mathrm{ppm}_{\mathrm{v}} \mathrm{h}^{-1}\right)$. The catalyst's steady-state NO

141 conversion $\left([\mathrm{NO}]_{\text {conversion }}\right)$ was calculated as follows:

$$
[N O]_{\text {conversion }}(\%)=\frac{[N O]_{\text {inlet }}-[N O]_{\text {outlet }}}{[N O]_{\text {in let }}} \times 100 \%
$$

143

144 Where $[N O]_{\text {inlet }}$ and $[N O]_{\text {outlet }}$ are the inlet and outlet $\mathrm{NO}$ concentrations $\left(\mathrm{ppm}_{\mathrm{v}}\right)$, respectively.

145 Adsorption capacity of the samples was determined as described elsewhere [37]. 


\begin{tabular}{|c|c|c|c|}
\hline Zeolites & Supply & Composition /mole ratio & Crystalline $^{\mathrm{h}}$ \\
\hline $13 \mathrm{X}$ & $\begin{array}{c}\text { Sinopharm Chemical Reagent Co., } \\
\text { Ltd., China }\end{array}$ & $\mathrm{Na}^{+}$form, $\mathrm{SiO}_{2} / \mathrm{Al}_{2} \mathrm{O}_{3}=2.46$ & $\mathrm{Y}$ \\
\hline $5 \mathrm{~A}$ & Shanghai Zeolite Co., China & $\mathrm{Ca}^{2+}$ form, $\mathrm{SiO}_{2} / \mathrm{Al}_{2} \mathrm{O}_{3}=2$ & Y \\
\hline $\mathrm{MCM}-41^{\mathrm{a}}$ & Prepared in laboratory & $\mathrm{Na}^{+}$form, $\mathrm{SiO}_{2} / \mathrm{Al}_{2} \mathrm{O}_{3}=30$ & $\mathrm{~N}$ \\
\hline SAPO- $11^{\text {b }}$ & Nankai Catalyst Co., Ltd., China & $\underline{\mathrm{SiO}}_{2} \underline{\mathrm{Al}}_{2} \underline{\mathrm{O}}_{3} \underline{\mathrm{P}}_{2} \underline{\mathrm{O}}_{5}=0.38: 1: 0.71$ & Y \\
\hline $\mathrm{SAPO}-5^{\mathrm{c}}$ & Prepared in laboratory & $\underline{\mathrm{SiO}}_{2} \underline{\mathrm{Al}}_{2} \underline{\mathrm{O}}_{3} \underline{\mathrm{P}}_{2} \underline{\mathrm{O}}_{5}=0.2: 1: 0.97$ & Y \\
\hline $\mathrm{NaY}$ & Zibo Catalyst Co., China & $\mathrm{Na}^{+}$form, $\mathrm{SiO}_{2} / \mathrm{Al}_{2} \mathrm{O}_{3}=5.6$ & $\mathrm{Y}$ \\
\hline USY & Zibo Catalyst Co., China & $\mathrm{H}^{+}$form, $\mathrm{SiO}_{2} / \mathrm{Al}_{2} \mathrm{O}_{3}=10$ & $\mathrm{Y}$ \\
\hline FER & Zeolyst International, USA & $\begin{array}{c}\mathrm{NH}_{4}{ }^{+} \text {form, } \mathrm{SiO}_{2} / \mathrm{Al}_{2} \mathrm{O}_{3}=20 \\
\mathrm{CP} 914 \mathrm{C}\end{array}$ & Y \\
\hline $\mathrm{ZSM}-22^{\mathrm{d}}$ & Zhuoyue Co., Ltd., China & $\mathrm{SiO}_{2} / \mathrm{Al}_{2} \mathrm{O}_{3}=62$ & Y \\
\hline$\beta$-NK & Nankai Catalyst Co., Ltd., China & $\mathrm{Na}^{+}$form, $\mathrm{SiO}_{2} / \mathrm{Al}_{2} \mathrm{O}_{3}=25$ & Y \\
\hline$\beta$-ZB & $\begin{array}{l}\text { Qingdao Yingrui Ind. \& Trade, } \\
\text { Co., Ltd., China }\end{array}$ & $\mathrm{Na}^{+}$form $\mathrm{SiO}_{2} / \mathrm{Al}_{2} \mathrm{O}_{3}=25$ & Y \\
\hline ZSM-5-a & Lanzhou, China & $\mathrm{SiO}_{2} / \mathrm{Al}_{2} \mathrm{O}_{3}=388$ & $\mathrm{Y}$ \\
\hline MOR & Nankai Catalyst Co., Ltd, China & $\mathrm{NH}_{4}^{+}$form, $\mathrm{SiO}_{2} / \mathrm{Al}_{2} \mathrm{O}_{3}=25$ & Y \\
\hline ZSM-5-b & Zeolyst International, USA & $\begin{array}{c}\mathrm{NH}_{4}^{+} \text {form, } \mathrm{SiO}_{2} / \mathrm{Al}_{2} \mathrm{O}_{3}=50 \\
\mathrm{CBV} 5524 \mathrm{G}\end{array}$ & $\mathrm{Y}$ \\
\hline SAPO- $34^{\mathrm{e}}$ & Nankai Catalyst Co., Ltd., China & $\underline{\mathrm{SiO}}_{2} \underline{\mathrm{Al}}_{2} \underline{\mathrm{O}}_{3} \underline{\mathrm{P}}_{2} \underline{\mathrm{O}}_{5}=0.6: 1: 0.837$ & Y \\
\hline $\operatorname{MCM}-22^{\mathrm{f}}$ & Prepared in laboratory & $\mathrm{SiO}_{2} / \mathrm{Al}_{2} \mathrm{O}_{3}=30$ & Y \\
\hline ZSM-5-c & Nankai Catalyst Co., Ltd., China & $\mathrm{H}^{+}$form, $\mathrm{SiO}_{2} / \mathrm{Al}_{2} \mathrm{O}_{3}=38$ & $\mathrm{Y}$ \\
\hline $\mathrm{ACFC}-10^{\mathrm{g}}$ & $\begin{array}{c}\text { American Technical Trading, Co., } \\
\text { USA }\end{array}$ & Carbon $=94 \mathrm{wt} \%$ & $\mathrm{~N}$ \\
\hline
\end{tabular}

$148{ }^{\mathrm{b}}$ SAPO-11 was purchased with the template and then subjected to calcination at $600{ }^{\circ} \mathrm{C}$ for $12 \mathrm{~h}$ with a ramp

149 of $2{ }^{\circ} \mathrm{C} \mathrm{min}{ }^{-1}$ in air atmosphere;

$150 \quad{ }^{\mathrm{c}}$ SAPO-5 was prepared according to [40];

$151{ }^{\mathrm{d}} \mathrm{ZSM}-22$ was calcined at $350{ }^{\circ} \mathrm{C}$ for $1 \mathrm{~h}$ then at $550{ }^{\circ} \mathrm{C}$ for $12 \mathrm{~h}$ in pure $\mathrm{O}_{2}$ atmosphere;

$152{ }^{\mathrm{e}}$ As-purchased SAPO-34 was calcined at $350{ }^{\circ} \mathrm{C}$ for $1 \mathrm{~h}$ then at $550{ }^{\circ} \mathrm{C}$ for $5 \mathrm{~h}$ in air atmosphere;

$153{ }^{\mathrm{f}} \mathrm{MCM}-22$ was provided by Tianjin University;

$154{ }^{\mathrm{g}}$ ACFC-10, activated carbon fiber cloth: batch ACC-5092-10.

$155{ }^{\mathrm{h}}$ XRD patterns are provided in supporting information. 
161 After stirring in a water bath at $80{ }^{\circ} \mathrm{C}$ for $30 \mathrm{~min}$, the suspension was cooled to room temperature, and the products were obtained after filtration, washing with water, and drying at $100{ }^{\circ} \mathrm{C}$ for $>8 \mathrm{~h}$. The products are described as ZSM-5-c-X, where $\mathrm{X}$ represents the molarity of

$\mathrm{NaOH}$. The relative crystallinity was determined based on procedure $\mathrm{B}$ described in ASTM d5758-01 [43].

\subsection{Description of Zeolites' Channels and Cages}

167 Physical properties of zeolites are classified using the following terminology. Maximum free sphere diameter $\left(D_{\max }\right)$ represents the largest spherical molecule that can pass through a zeolite channel along a given crystallographic axis $(a, b$, or $c)$ [44]. Maximum included sphere diameter $\left(D_{i}\right)$ represents the largest spherical molecule that can fit in a zeolite cage with volume ( $\left.V_{\text {cage }}\right)$, assuming the cage is spherical:

$$
V_{\text {cage }}=\pi D_{i}^{3} / 6
$$

174 See Supporting Information (Figure S1) for graphical descriptions of the channels and cages. 

investigated the reaction of $\mathrm{O}_{2}$ and NO using $a b$ initio wave functional methods [39]. In

this research, the volume of this TS was calculated using density functional theory

(DFT). These calculations were completed at the B3LYP/6-31G (d) level using Gaussian

software (2003) [45]. The structure of TS was optimized using CCSD (T) and CASSCF

methods, and the volume of this TS was computed as the volume inside a contour of

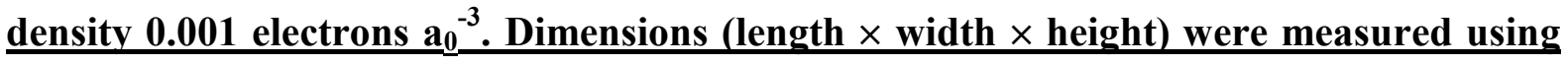

$\underline{\AA \text { and } 1.52 \AA \text {, respectively }[46] \text {, and were used for calculating the TS's dimensions. }}$

187 The crystal patterns of zeolites were obtained using X-ray diffraction (XRD, BRUKER D-5000) with $\mathrm{Cu} \mathrm{K \alpha}$ radiation, a step size of $0.02^{\circ}$, and a scan range of $5-50^{\circ}$ with a scan rate

189 of $2^{\circ} \min ^{-1}$. Sample porosity was measured with $\mathrm{N}_{2}$ adsorption on a Micrometrics surface analyzer (Tristar 3000 ) at $-196{ }^{\circ} \mathrm{C}$. Prior to analysis, the samples were degassed at $300{ }^{\circ} \mathrm{C}$ for $>$

$1916 \mathrm{~h}$. Total pore volume was obtained at a relative pressure of 0.98 , total surface area was

192 calculated by BET method, and micropore surface area and micropore volume were calculated

193 with the t-plot method.

194 3. Results and Discussions

\subsection{Temperature-Dependent NO Conversion}

196 Steady-state NO conversions for the tested zeolites at $25^{\circ} \mathrm{C}$ and $50{ }^{\circ} \mathrm{C}$ are described in Figure

197 1. ZSM-5-a/b, SAPO-34, MCM-22, ZSM-22, $\beta$ and MOR oxidize $25 \%$ to $40 \%$ of NO at $25{ }^{\circ} \mathrm{C}$, 
198 while the other zeolites oxidize $<25 \%$ of the NO at the same temperature. NO conversions for

199 the most active zeolites (MCM-22 and SAPO-34) at $50^{\circ} \mathrm{C}$ are $16.2 \%$ to $17.1 \%$, which are

$200 \underline{28}$ to $30 \%$ of those for activated carbon catalyst $\left(\mathbf{5 7 \%}, \mathbf{5 0}{ }^{\circ} \mathbf{C}\right)$ [38]. NO conversion shows a

201 negative temperature dependence for all zeolites except $\mathrm{NaY}$ and 13X. This negative

202 dependence of NO conversion on temperatures is attributed to their negative activation

203 energies [20]. This negative trend, which differs from observations for metal oxide catalyzed

204 NO oxidation, implies that the reaction mechanism may not follow traditional Eley-Rideal or

205 Langmuir-Hinschelwood pathways [47]. Regarding NaY and 13X, lower conversion at lower

206 temperature, indicates an apparent positive activation energy for $\mathrm{NaY}$ and $13 \mathrm{X}$ catalyzed NO

207 oxidation. This opposite trend indicates the existence of either a different reaction

mechanism and/or the loss of catalytic sites at lower temperatures. For zeolites with a

209 high concentration of $\mathrm{Na}^{+}$, such as $\mathbf{1 3 X}$ and $\mathrm{NaY}$, Loiland $e t$ al. proposed an $\mathrm{Na}^{+}-$

210 mediated pathway that enhances $\mathrm{NO}^{+}$adsorbed species during NO oxidation, improving

211 overall conversion [34]. This pathway, however, also has negative activation energy and

212 therefore cannot explain the inverse temperature dependence observed for $13 \mathrm{X}$ and $\mathrm{NaY}$.

213 Another possibility is that the high NO ${ }_{x}$ adsorption capacities of NaY and 13X (1778

$214 \underline{\mu m o l ~} \mathrm{~g}^{-1}$ and $2043 \mu \mathrm{mol} \mathrm{g}^{-1}$ at $25^{\circ} \mathrm{C}$, respectively), resulting from accessible $\mathrm{Na}^{+}$ions

215 located in $\mathrm{S}_{\text {III }}$ and $\mathrm{S}_{\text {III positions }}$ [48], cause blockage of microporosity, decreasing

216 conversion at low temperatures more significantly than at higher temperatures [49].

217 Loiland et al. similarly hypothesized this possibility: NO$\underline{2}_{2}$ inhibition may have caused 
219 lower temperatures [34].

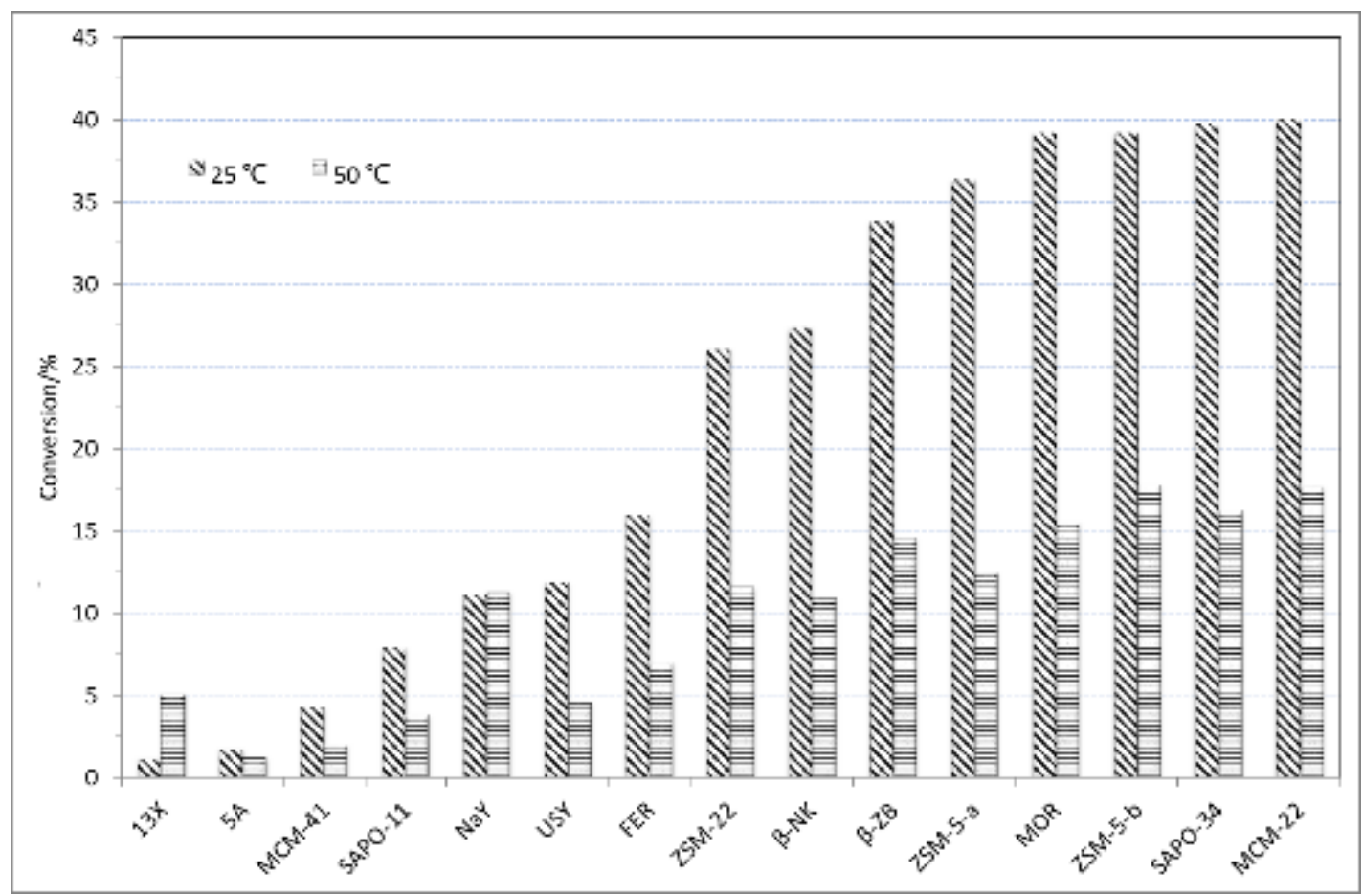

Figure 1 Steady-state NO conversion over select zeolites at $25^{\circ} \mathrm{C}$ and $50{ }^{\circ} \mathrm{C}$. SAPO-5 and

ZSM-5-c are not included because the test at $50{ }^{\circ} \mathrm{C}$ did not occur due to insufficient availability of SAPO-5 and ZSM-5-c

\subsection{Chemical Composition-Performance Relationship}

For all the zeolites, except for ZSM-5-b, FER, MOR, and USY, outlet [NO] immediately

226 decreases (the first local minimum), then increases (within $60 \mathrm{sec}$, Figure S3) to a peak before

227 decreasing again to a stable concentration $\left(1 \mathrm{ppm}_{\mathrm{v}} \mathrm{h}^{-1}\right.$ change, Figure S4). The peak in outlet

228 [NO] curve is attributed to $\mathrm{NO}_{2}$ disproportionation associated with the formation of $\mathrm{NO}^{+}$and

$229 \mathrm{NO}_{3}{ }^{-}$during $\mathrm{NO}_{2}$ adsorption with zeolites [50], which is consistent with results for

230 carbonaceous $\mathrm{NO}$ oxidation catalysts [37]. Outlet $\left[\mathrm{NO}_{2}\right]$ increases to a stable concentration $(<$

$2311 \mathrm{ppm}_{\mathrm{V}_{-}} \mathrm{h}^{-1}$ change) after breakthrough $(0-35 \mathrm{~h}$, depending on the zeolite) (Figure $\mathrm{S} 4)$. 
232 The second local minimum in [NO] is observed for ZSM-5-b, FER, MOR, and USY zeolites.

233 This behavior is not consistent with other NO oxidation catalysts and may be related to

234 the $\mathrm{NH}_{4}{ }^{+}$cation present on these materials. $\mathrm{NH}_{4}{ }^{+}$can cause $\mathrm{NO}_{\mathrm{x}}$ reduction, impacting the

235 effluent concentration profiles [32]. By inference, the composition of zeolites, including the

236 presence of cations, may influence transient NO oxidation kinetics, including outlet [NO] and

$237\left[\mathrm{NO}_{2}\right]$ profiles, and the time to achieve steady-state conditions at $25{ }^{\circ} \mathrm{C}$ (Figure 1, Table S1)

238 and $50{ }^{\circ} \mathrm{C}$ (Figure 2, Figure S5, Table2). The high $\mathrm{NO}_{2}$ adsorption capacities of $\mathrm{NaY}$ and $13 \mathrm{X}$

239 are attributed to the presence of $\mathrm{Na}^{+}$, which also increases the corresponding breakthrough

240 time because of strong acid-base interactions [51]. MCM-41 with less $\mathrm{Na}^{+}$than $\mathrm{NaY}$ and $13 \mathrm{X}$

241 based on the $\mathrm{Si} / \mathrm{Al}$ molar ratio, also has increased $\mathrm{NO}_{2}$ breakthrough time (and time to achieve

242 steady-state conditions) but less total $\mathrm{NO}_{\mathrm{x}}$ adsorption capacity. 


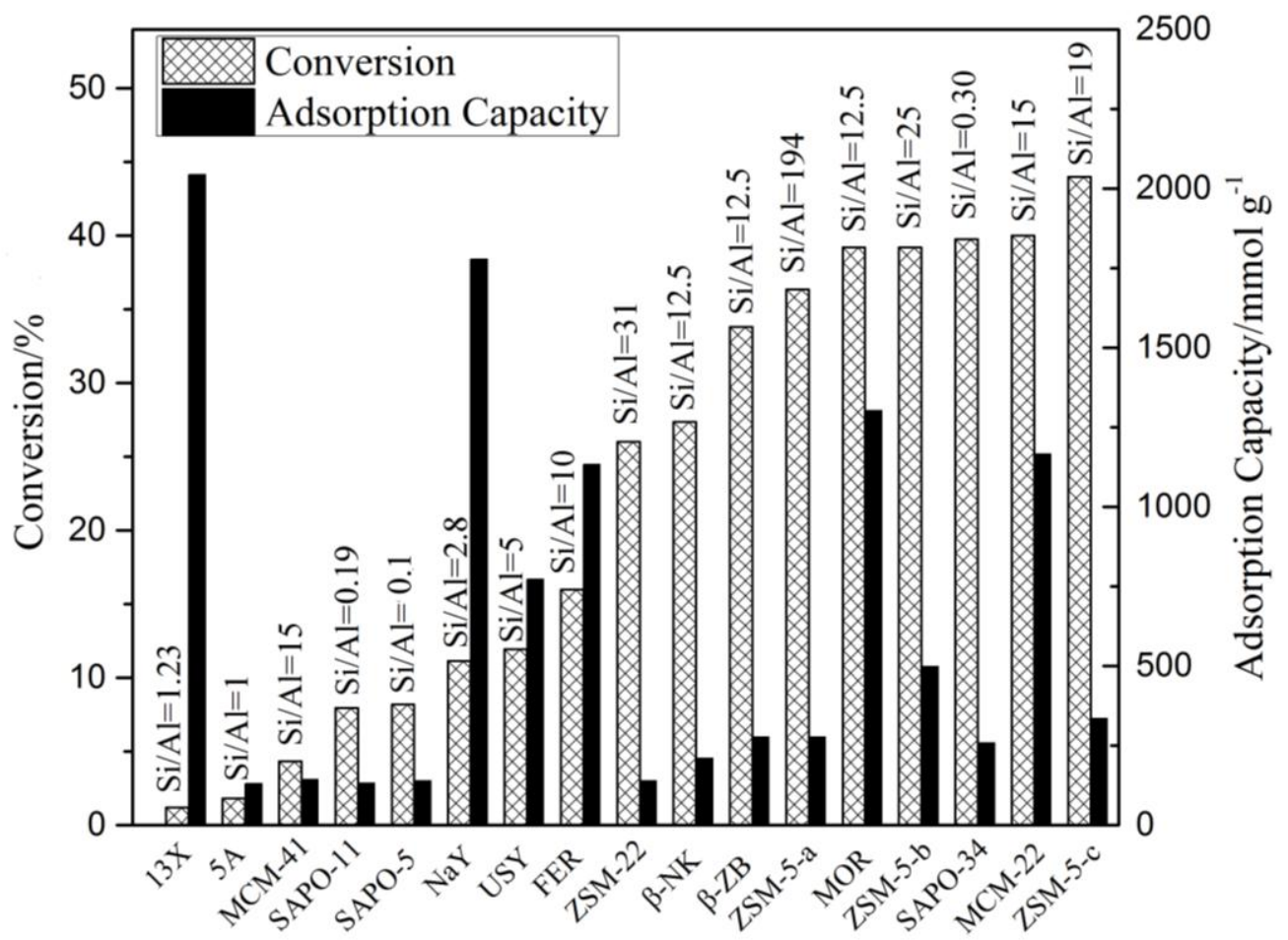

246 Figure 2 Relationship between steady-state NO conversion, and adsorption capacity, and $\mathrm{Si} / \mathrm{Al}$ molar ratio for select zeolites $\left(25^{\circ} \mathrm{C}\right)$

248 In zeolite synthetic chemistry, compensated cations were incorporated into the zeolite matrix

249 to balance the charge brought by aluminum tetrahedrons. The resulting compensated ions,

250 varying with $\mathrm{Si} / \mathrm{Al}$ molar ratio, can influence transient $\mathrm{NO}$ oxidation kinetics as detailed above.

251 However, $\mathrm{Si} / \mathrm{Al}$ molar ratio is not expected to have same influence on steady-state NO

252 conversion (Figure 2 \& Figure S5). For example, ZSM-5-a/b/c have similar steady-state

253 NO conversion (36.4\% -44.0\%) despite an order of magnitude range in Si/Al molar ratio.

254 In terms of transient NO oxidation kinetics, more time is required to reach steady-state

255 for ZSM-5-b $(\mathrm{Si} / \mathrm{Al}=25)$ and $\mathrm{ZSM}-5-\mathrm{c}(\mathrm{Si} / \mathrm{Al}=18)$ compared with $\mathrm{ZSM}-5-\mathrm{a}(\mathrm{Si} / \mathrm{Al}=194)$,

256 because a lower $\mathrm{Si} / \mathrm{Al}$ ratio is associated with more compensated cations, which facilitates

257 NO $x$ adsorption. For steady-state NO conversion, lower Si/Al molar ratio for the ZSM-5

258 catalysts results in higher conversion, indicating that, within a given zeolite framework

259 (i.e., constant $D_{i}$ and $D_{\max }$, Table 2 ), Si/Al molar ratio may have an impact on NO

260 conversion. This is consistent with Loiland et al.'s findings that show cations $\left(\mathrm{Na}^{+}\right)$ 
(MFI), $\beta(* B E A)$ and SAPO-34 (CHA) have a wide range of Si/Al molar ratios (0.3 to 194)

and topologies, however, they all perform effectively $(25-40 \%)$ once steady-state

conditions are achieved [35]. Particularly, 13X and 5A with a Si/Al molar ratio < 2, show

a lower conversion $(<3 \%)$, while SAPO-34 with a Si/Al molar ratio of 0.3 has a

conversion of $39.8 \%$. That is, lower $\mathrm{Si} / \mathrm{Al}$ is not expected to have higher conversion,

indicating the influence of $\mathrm{Si} / \mathrm{Al}$ molar ratio on NO conversion is less significant than that

of other factors (e.g., pore volume, pore size, as discussed later). However, the

contribution of $\mathrm{Si} / \mathrm{Al}$ ratio to NO conversion should be identified for a series of zeolites

with the same topologies and approximate physical properties in the future.

\subsection{Structure-Performance Relationship}

As previously mentioned [12, 38], activated carbon fiber cloth's physical properties control

the catalyst's steady-state NO conversion [37]. Results to this point demonstrate that the zeolite's chemical properties do not provide consistent impact on the steady-state NO conversion. It is therefore beneficial to investigate the relationship involving steady-state NO conversion and the physical properties of the catalysts. Steady-state NO conversion was plotted against surface area, pore volume, $\underline{\max }_{\underline{\operatorname{mat}}}$ and $D_{i}$ of the fresh zeolite catalysts that were determined before NO oxidation tests (Figure 3a-d, respectively). 
284 but their NO conversions differ by $59 \%$, indicating that the framework of the zeolite (i.e., the

285 distribution of void space provided by channels and cages) needs to be considered when

286 predicting steady-state NO conversion. These results are once again consistent with studies

287 investigating activated carbon catalysts for NO oxidation - high conversion is not controlled

288 by the bulk physical properties (i.e., surface areas or pore volumes) of the catalyst [12]. A

289 narrow range of pore widths $(5 \AA-7 \AA)$ were important for activated carbon fibers to achieve

290 larger steady-state NO conversion, and such observation should be investigated with zeolites,

291 where void space can be dominated by narrow channels (e.g., MOR, ZSM-22) or large cages

292 (e.g., SAPO-34), or be evenly distributed between the two geometries (e.g., MCM-22) (Table

293 2). This makes it particularly important to identify individual contributions due to the sizes of

294 the channels $\left(D_{\max }\right)$ and cages $\left(D_{i}\right)$ rather than relying on bulk properties (i.e., surface area and

295 pore volume, Figure 3a-b, respectively). 

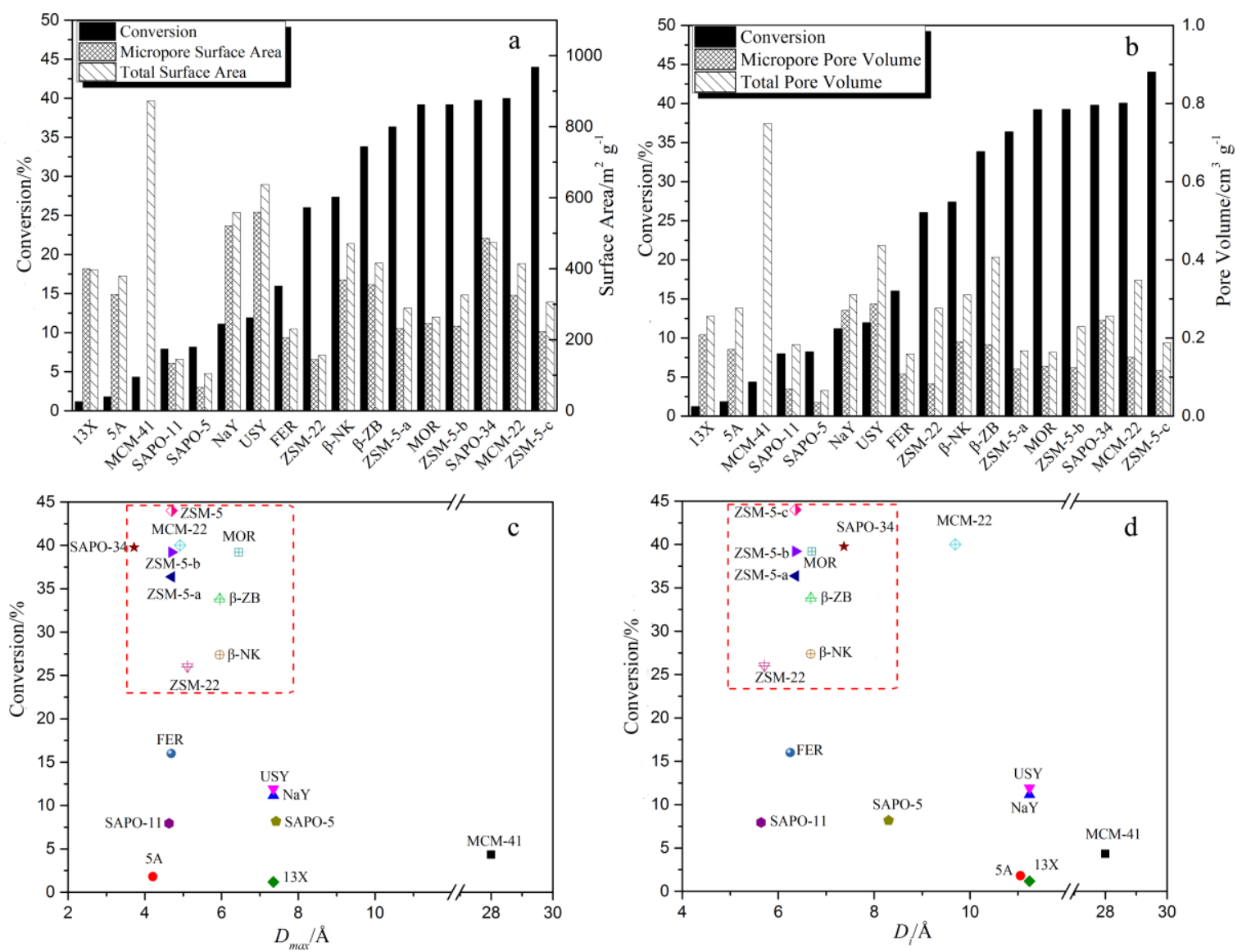

296

297 Figure 3 Fresh zeolite structure-NO conversion relationship $\left(25^{\mathbf{0}} \mathrm{C}\right)$ versus: a) total and

298 micropore surface areas, b) total and micropore pore volumes, c) maximum free sphere

299 diameter $\left(D_{\max }\right)$, and d) maximum included sphere diameter $\left(D_{i}\right)$. 
Table 2 Topological information and physical properties of select zeolites [44]

301

\begin{tabular}{|c|c|c|c|c|c|c|c|c|c|c|c|}
\hline \multirow{2}{*}{ Zeolite } & \multirow{2}{*}{$\begin{array}{c}\text { Code } \\
\text { Structure }\end{array}$} & \multirow{2}{*}{$\mathrm{MR}^{\mathrm{a}}$} & \multirow{2}{*}{$\begin{array}{l}D_{i}^{\mathrm{b}} \\
/ \AA\end{array}$} & \multirow{2}{*}{$\mathrm{n} D^{\mathrm{c}}$} & \multicolumn{3}{|c|}{$\begin{array}{c}D_{\max }^{\mathrm{d}} \\
/ \AA \\
\end{array}$} & \multirow{2}{*}{$\begin{array}{c}\text { Total Surface } \\
\text { Area } \\
/ \mathrm{m}^{2} \mathrm{~g}^{-1}\end{array}$} & \multirow{2}{*}{$\begin{array}{c}\text { Micropore } \\
\text { Surface Area } \\
/ \mathrm{m}^{2} \mathrm{~g}^{-1}\end{array}$} & \multirow{2}{*}{$\begin{array}{l}\text { Total Pore } \\
\text { Volume } \\
/ \mathrm{cm}^{3} \mathrm{~g}^{-1}\end{array}$} & \multirow{2}{*}{$\begin{array}{l}\text { Micropor } \\
\text { Volume } \\
/ \mathrm{cm}^{3} \mathrm{~g}^{-1}\end{array}$} \\
\hline & & & & & $\begin{array}{c}a \\
\text { axis }\end{array}$ & $\begin{array}{c}b \\
\text { axis }\end{array}$ & $\begin{array}{c}c \\
\text { axis }\end{array}$ & & & & \\
\hline $13 \mathrm{X}$ & FAU & 12-MR & 11.24 & 3 & 7.35 & 7.35 & 7.35 & 397 & 400.0 & 0.255 & 0.207 \\
\hline $5 \mathrm{~A}$ & LTA & $8 \mathrm{MR}$ & 11.05 & 3 & 4.21 & 4.21 & 4.21 & 379 & 327 & 0.276 & 0.170 \\
\hline MCM-41 & N/A & N/A & 28 & 1 & N/A & N/A & $\mathrm{N} / \mathrm{A}^{\mathrm{e}}$ & 872 & $0^{\mathrm{g}}$ & 0.749 & $0^{\mathrm{f}}$ \\
\hline SAPO-11 & AEL & $10 \mathrm{MR}$ & 5.64 & 1 & 4.63 & 2.01 & 2.01 & 145 & 134 & 0.183 & 0.069 \\
\hline SAPO-5 & AFI & $12 \mathrm{MR}$ & 8.30 & 1 & 2.22 & 2.22 & 7.42 & 105 & 65.9 & 0.065 & 0.034 \\
\hline $\mathrm{NaY}$ & FAU & 12-MR & 11.24 & 3 & 7.35 & 7.35 & 7.35 & 558 & 521 & 0.310 & 0.270 \\
\hline USY & FAU & 12-MR & 11.24 & 3 & 7.35 & 7.35 & 7.35 & 637 & 559 & 0.437 & 0.287 \\
\hline FER & FER & $10 \mathrm{MR}$ & 6.25 & 2 & 1.56 & 3.40 & 4.69 & 230 & 205 & 0.159 & 0.107 \\
\hline ZSM-22 & TON & $10 \mathrm{MR}$ & 5.71 & 1 & 2.31 & 1.56 & 5.11 & 144 & 156 & 0.276 & 0.082 \\
\hline$\beta$-NK & $*$ BEA & $12 \mathrm{MR}$ & 6.68 & 3 & 5.95 & 5.95 & 5.95 & 470 & 368 & 0.310 & 0.190 \\
\hline$\beta-Z B$ & *BEA & $12 \mathrm{MR}$ & 6.68 & 3 & 5.95 & 5.95 & 5.95 & 416 & 355 & 0.406 & 0.183 \\
\hline ZSM-5-a & MFI & $10 \mathrm{MR}$ & 6.36 & 3 & 4.70 & 4.46 & 4.46 & 326 & 231 & 0.167 & 0.120 \\
\hline MOR & MOR & $12 \mathrm{MR}$ & 6.70 & 1 & 1.57 & 2.95 & 6.45 & 264 & 246 & 0.163 & 0.127 \\
\hline ZSM-5-b & MFI & $10 \mathrm{MR}$ & 6.36 & 3 & 4.70 & 4.46 & 4.46 & 290 & 238 & 0.229 & 0.123 \\
\hline SAPO-34 & CHA & $8 \mathrm{MR}$ & 7.37 & 3 & 3.72 & 3.72 & 3.72 & 474 & 486 & 0.256 & 0.245 \\
\hline MCM-22 & MWW & $10 \mathrm{MR}$ & 9.69 & 2 & 4.92 & 4.92 & 2.60 & 415 & 325 & 0.347 & 0.150 \\
\hline ZSM-5-c & MFI & $10 \mathrm{MR}$ & 6.36 & 3 & 4.70 & 4.46 & 4.46 & 306 & 223 & 0.187 & 0.116 \\
\hline
\end{tabular}

$302{ }^{\mathrm{a}}$ Member rings. ${ }^{\mathrm{b}}$ Maximum included sphere diameter. ${ }^{\mathrm{c}}$ Pore dimensions. ${ }^{\mathrm{d}}$ Maximum free sphere diameter. ${ }^{\mathrm{e}}$ Not applicable. ${ }^{\mathrm{f}}$ MCM-41 is a

303 typical mesoporous material. 
$304 D_{\max }$ identifies the catalyst's channel width and provides an upper limit that prevents or

305 allows gas diffusion into or out of void spaces (sum of channel and cage) (Table 2). The eight

306 tested zeolites with highest steady-state NO conversions $(25.0-40.0 \%)$, including ZSM-5-a/b

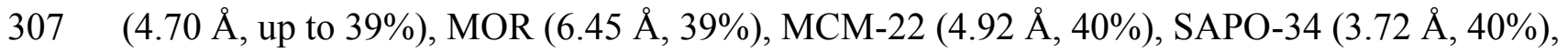

$308 \beta$-NK/ZB (5.95 $\AA$, up to 34\%) and ZSM-22 (5.11 $\AA, 26 \%$ ) (Figure 3c), have $D_{\max }$ values

309 between 3.72 and $6.45 \AA$. This range of channel widths allows void space to be penetrated by

310 the reactants $\left(\mathrm{NO}=3.17 \AA, \mathrm{O}_{2}=3.46 \AA\right)$, while also allowing for the release of the $\mathrm{NO}$

311 oxidation product $\left(\mathrm{NO}_{2}=3.40 \AA\right)$ [52].

312 Total void space and the distribution of void spaces provided by channels/cages should be

313 incorporated into predictions for steady-state NO conversion by considering more than $D_{\max }$

314 since it represents the smallest width of channels connecting zeolite cages (or the overall,

315 average channel width in zeolites without cages). For example, SAPO-34 has a high

316 steady-state NO conversion (40\%). However, because channels contribute $<10 \%$ of

317 SAPO-34's void space, its strong performance cannot be attributed to its desirable $D_{\max }$. A

318 similar argument is valid for zeolite 5A, which has a low steady-state NO conversion of $1.8 \%$

319 despite its desirable $D_{\max }$ value of $4.21 \AA$. Prediction of NO conversion of zeolite catalysts

320 should be based on more than $D_{\max }$. The appropriate value of $D_{\max }$ allows the relevant

321 reactants and products to pass through the zeolite's channels resulting in the first selection

322 rule for choosing zeolite catalysts for NO oxidation that $D_{\max }$ is not less than $3.46 \AA$.

323 As previously mentioned, $D_{i}$, represents the largest spherical molecule that can fit in a

324 zeolite cage with volume $\left(V_{\text {cage }}\right)$ and should be investigated for its impact on NO oxidation 
325 (Figure 3d). Steady-state NO conversion decreases with increasing $D_{i}$. However, MCM-22

326 and SAPO-11 are exceptions to this trend, having notably high and low conversions (40\%

327 and 7.9\%, respectively). Effective zeolites with steady-state NO conversions ranging from

$32826.0 \%$ to $39.8 \%$ (e.g., ZSM-5, MOR, $\beta$, ZSM-22, and SAPO-34) have $D_{i}$ values between

$329 \quad 5.71$ and $7.37 \AA$.

$330 \quad$ FER and ZSM-5 have similar $D_{i}$ values $(6.25$ and $6.36 \AA)$ and micropore volumes $(0.159$

331 and $0.167 \mathrm{~cm}^{3} \mathrm{~g}^{-1}$ ), but at steady-state conditions, FER oxidizes 56\% less NO than ZSM-5-a.

332 This discrepancy may be attributed to topological differences. FER cages are circumscribed

333 by 8 ring channels along the $b$ axis $\left(D_{\max }=3.40 \AA\right.$, Figure $\left.\mathrm{S} 1\right)$. These windows that provide

334 the transitions between cages and channels may not be large enough to accommodate the TS

335 formed or required for the oxidation reaction to proceed (this topic is described in more detail

336 below). ZSM-5-a has a more reasonable $D_{\max }$ value (across all axes), allowing

337 reactants/products/intermediates to be accommodated in cages and channels, allowing for

338 higher steady-state NO conversion due to more effective utilization of void space. MCM-22

339 has surprisingly high conversion despite a large $D_{i}(9.69 \AA)$. Analyzing MCM-22 topology, it

340 is observed that MCM-22 has a void space with an appropriate $D_{\max }(4.92 \AA)$, which accounts

341 for $45 \%$ of its void space [53], and $4.92 \AA$ is in the range of $D_{\max }$ values for effective

342 conversion. When predicting steady-state NO conversion, it is important to consider both

343 channel and cage dimensions for zeolites that incorporate both structures. 
344 The concentrated zone describing large NO conversions for ranges in $D_{i}$ and $D_{\max }$ (Figure

345 3), and interpretations for outliers, indicate that zeolites can be effective for NO oxidation if 346 they have $4.70<D_{\max }<6.45 \AA$ or $5.71<D_{i}<7.37 \AA$.

347 It is also important to assess the relevance of pore volume to steady-state NO conversion.

348 ZSM-5 after alkaline treatment provides a range of microporosity and mesoporosity values

349 (Figure 4). Since ZSM-5 has desirable $D_{i}$ and $D_{\max }$ values, increasing the volume of active 350 micropores (without altering their pore widths) is expected to increase steady-state NO

351 conversion. Figure 4a shows that increasing the zeolite's crystallinity and micropore volume

352 cause increases in steady-state NO conversion (Table S3 and Figure S6). Conversely, added

353 mesoporosity does not improve a zeolite's steady-state NO conversion (Figure $4 \mathrm{~b}$ ). It is

354 expected that micropores are most active for NO oxidation, which is consistent with

355 Artioli et al.'s study showing that amorphous silica with mesoporosity is less effective

356 than microporous zeolites (CHA, BEA, and SIL-1D) [31]. Large pore volume is expected

357 to provide high conversion, however, increasing mesopore volume at the expense of

358 micropore volume decreases conversions. The distinct increase in conversion for

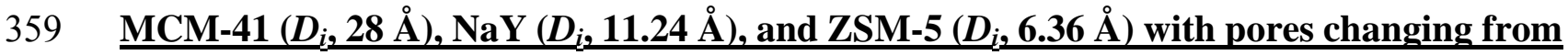

360 mesopores to micropores, suggests that the influence of microporosity is more significant

361 than that of mesoporosity, corroborating the findings on alkali-treated zeolites. Also,

362 hydroxyl groups that were added during alkaline treatment do not increase the catalyst's

363 conversion. Therefore, hydroxyl groups are not required for zeolite-catalyzed NO oxidation 
364 [22, 33], confirming earlier results that physical properties control steady-state NO 365 conversion.
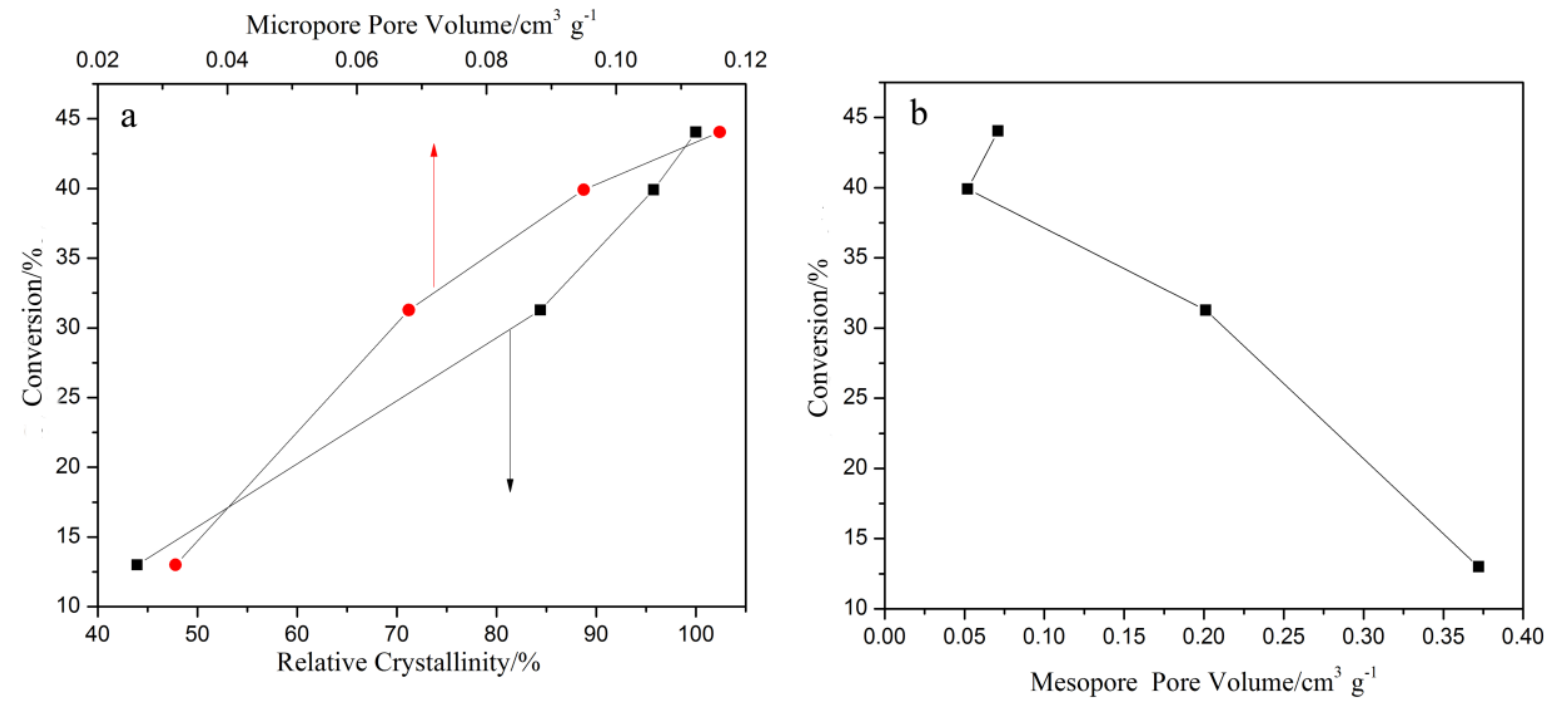
volume, and b) mesopore pore volume of alkali-treated ZSM-5

\subsection{Comparisons between Activated Carbon Fibers and Zeolites} conversion of the catalyst. For activated carbon fibers, chemical properties including acidity surface functional groups and bulk composition impact transient oxidation kinetics without altering steady-state NO conversion and such property is consistent with observations for zeolites [34]. To highlight the similarities between the activated carbons and zeolites, psudeo turnover frequency (TOF) was determined for the activated carbons and zeolites with small channel and/or cage widths $(<7 \AA)$. This calculation standardizes the catalysts' steady-state 
NO conversion by normalizing to micropore volumes. Despite the obvious chemical

381 differences between carbon and zeolite materials (Table 1), the pseudo TOF values are rather

383 larger channel and/or cage width (> $7 \AA$ ) deviate from this trend. This observation suggests

384 that a similar NO oxidation reaction mechanism exists for these two groups of catalysts and

385 stresses that the physical properties, and not the chemical properties, of the catalyst control

386 steady-state NO conversion.

$$
\text { Table } 3 \text { Micropore volume, NO conversion, and pseudo turnover frequency (Pseudo }
$$
TOF) ${ }^{\mathrm{a}}$ values for zeolites and activated carbon fiber cloth (ACFC) at $50{ }^{\circ} \mathrm{C}$

\begin{tabular}{ccccc:c}
\hline & ZSM-22 & MOR & ZSM-5-a & USY & ACFC-10 \\
\hline $\begin{array}{c}\text { Micropore Volume/ } \\
\mathrm{cm}^{3} \mathrm{~g}^{-1}\end{array}$ & 0.08 & 0.13 & 0.12 & 0.29 & 0.40 \\
$\begin{array}{c}\text { Conversion/\% } \\
\begin{array}{c}\text { Reaction Rate/ } \\
\mu \text { mol g }\end{array}\end{array}$ & 11.6 & 15.5 & 12.4 & 4.6 & 57 \\
$\begin{array}{c}\text { Pseudo TOF/ } \\
\mu \text { mol h } \mathrm{cm}^{-1}\end{array}$ & 49.9 & 66.4 & 53.3 & 19.8 & 232 \\
\hline
\end{tabular}

${ }^{\mathrm{a}}$ Pseudo TOF $=$ pseudo turnover frequency $=$ reaction rate/micropore volume at steady-state conditions.

$390{ }^{\mathrm{b}}$ NO conversion of ACFC-10 was obtained elsewhere [38]

391 Activated carbon fiber-catalyzed NO oxidation includes two consecutive steps: 1) rapid NO

392 oxidation in micropores, and 2) reactive adsorption of $\mathrm{NO}_{2}$ onto the carbon surface. Similar

393 pseudo TOF values, $\mathrm{NO}_{2}$ evolution profiles, and time scales for activated carbon and zeolites

394 (Figure S7) indicate that this mechanism could be consistent for the activated carbon fiber and

395 zeolite materials tested here. Conversion associated with Step 1 is determined by the

396 catalyst's physical properties, however, the reaction mechanism how physical properties

397 impact the conversion is still not clear. 
399 Gadzhiev et al. reported that a two-step mechanism takes place entirely on the singlet state 400 potential surface: 1) $2 \mathrm{NO}+\mathrm{O}_{2} \rightarrow \mathrm{TS} 1 \rightarrow \mathrm{CC}$; 2) $\mathrm{CC} \rightarrow \mathrm{TS} 2 \rightarrow 2 \mathrm{NO}_{2}$, where TS1 and TS2 are NO

401 oxidation TSs and CC is a reaction intermediate [39] [39]. These authors also reported that

402 the first step is rate-determining with an estimated activation energy of $6.67 \mathrm{~kJ} \mathrm{~mol}^{-1}$, which is

403 consistent with experimental activation energy values, these authors also suggested the

404 activation energy is greater than zero because of a basis set superposition error (BSSE)

405 during simulation.

406 Increasing void space dimensions (i.e., $D_{\max }$ of zeolites where channels are dominant and $D_{i}$

407 of zeolites where cages are dominant) beyond critical ranges in zeolites decreases NO

408 conversion, highlighting the importance of adsorbate-adsorbent interaction. Non-specific van

409 der Waals interaction is highest when the dimensions of the adsorbate closely match that of

410 the accommodating void space. Increasing the dimensions of void space correspondingly

411 weakens the van der Waals interaction between TS and pore walls of the zeolites,

412 decreasing the catalyst's steady-state NO conversion. Results here are combined with

413 quantum simulations from others [39] to propose TS1 as the TS for NO oxidation and to

414 determine its associated free energy. The free energy of TS1 depends on the pore width of

415 activated carbons and the channel/cage width of zeolites. Altering the channel/cage width of

416 void spaces changes the activation energy required to form TS1 and correspondingly affects

417 Step 1 of the reaction mechanism and its associated steady-state NO conversion. This

418 concept of catalytic activity based on TS confinement in void spaces has been widely 
However, Artioli et al. recently proposed a confinement mechanism for NO oxidation

\section{two different homogenous routes [56].}

424 The estimated volume of TS1 is $70.1 \AA^{3}$ [36], and the corresponding spatial configuration of 425 atoms is shown in Figure 5. TS1 is three-dimensional with dimensions of $6.94 \AA \times 4.67 \AA \times$

$4264.46 \AA$, along the $x, y$, and $z$ axes, respectively (Table S4). Reported zeolites with high

427 conversion ( 25 to $40 \%$ for conditions tested here) have channels or cages that accommodate

428 TS1, including ZSM-5 (6.36 $\AA$ and $135 \AA^{3}$, cage width and volume), SAPO-34 (7.37 $\AA$ and $\left.429209 \AA^{3}\right), \operatorname{MOR}\left(6.70 \AA\right.$ and $\left.157 \AA^{3}\right)$, ZSM-22 $\left(5.71 \AA\right.$ and $\left.97.4 \AA^{3}\right)$, and $\beta(6.68 \AA$ and 156 $\left.430 \quad \AA^{3}\right)[44]$.

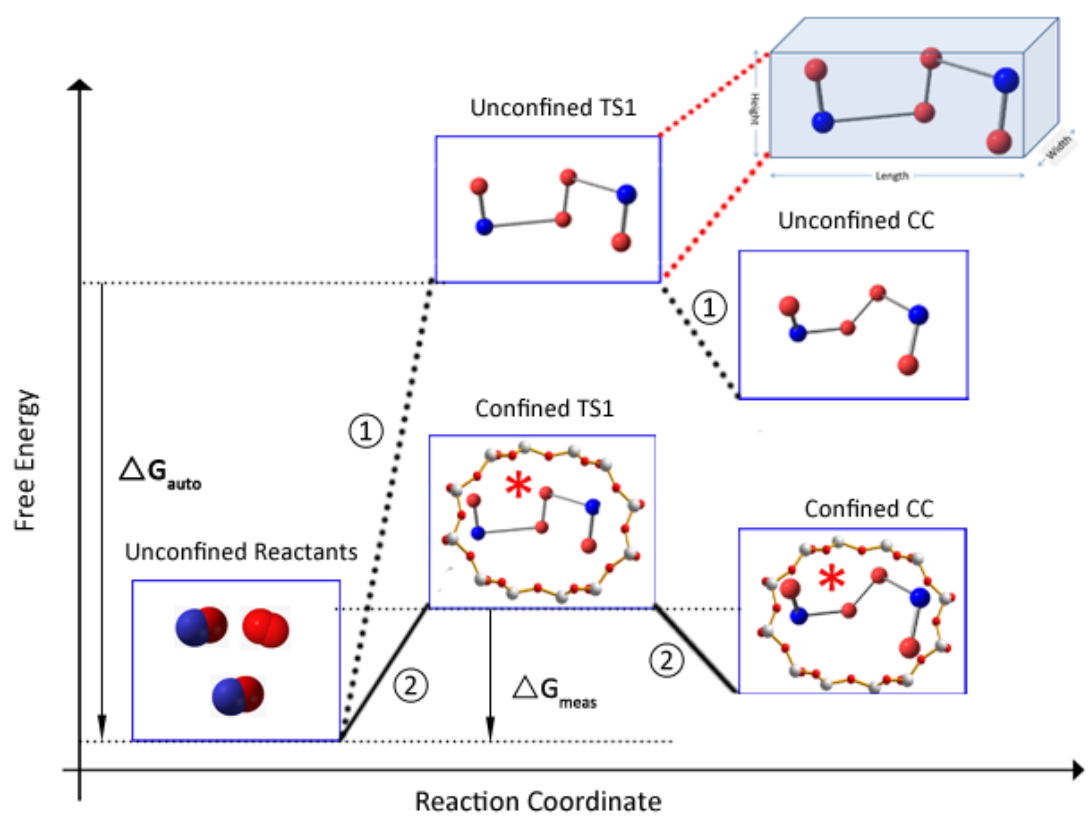



uncatalyzed oxidation pathway. Route (2) represents the pathway in the presence of zeolites. The inset describes the 3D spatial configuration of transient state (TS) derived from simulation, where red spheres represent oxygen and blue spheres represent nitrogen. The structure in the shaded box is the TS with length, width and height $\underline{\text { dimensions. }} \Delta \mathbf{G}_{\text {meas }}$ and $\Delta \mathbf{G}_{\text {auto }} \underline{\text { represent the differences between reactants and either }}$ confined TS and unconfined TS. Confined TS, marked with asterisk, indicates that the spatial configuration of TS is different from unconfined TS in spite of the same geometries shown in this figure. steady-state $\mathrm{NO}$ conversion $(40 \%)$. It is proposed that $\mathrm{NO}$ and $\mathrm{O}_{2}$ diffuse through the zeolite's narrow channels and into the more accommodating cages, where TS1 can freely form. $\mathrm{NO}$ and $\mathrm{O}_{2}$ do not readily react in SAPO-34 channels because they are too narrow for TS1. After the reaction occurs in the cages, the $\mathrm{NO}_{2}$ product diffuses back through the channels and is released. The same argument can be made for zeolite $5 \mathrm{~A}$, where narrow channels again prevent TS1 formation while allowing for diffusion of the reactants. However, in 5A (Table 2), the cages are too large to provide van der Waals interaction between the TS and the pore walls of the zeolite necessary for the reaction to proceed, preventing any notable oxidation. SAPO-34 and 5A provide a valuable comparison between zeolites with variable cage sizes and highlight the importance of van der Waals interactions to form TS1 - void spaces that are too small or too large are not effective for NO oxidation. These 
results also suggest that the TS is formed directly in the void space, rather than forming in the bulk gas phase and then transported to the more reactive void space. This direct formation of TS1 is expected to occur in channels or cages, if they are of appropriate dimensions. (2) NO oxidation. For Route (1), TS1 is formed slowly with an increased energy barrier,

TS1 in Route (2) is decreased due to being confined in a void space and the corresponding van der Waals interaction between TS1 and the pore walls of the zeolite.

According to transition state theory [57], reaction rates depend on the decomposition of TS1. Eqs. (3-4) and Eqs. (5-6) show the reaction rates and rate constants for uncatalyzed and zeolite catalyzed NO oxidation, respectively (details in supporting information).

$$
\begin{gathered}
r_{1}=k_{1}[N O]^{2}\left[O_{2}\right] \\
k_{1}=\frac{2 k_{B} T}{h} \exp \left(-\frac{\Delta G_{T S 1}-2 \Delta G_{N O}-\Delta G_{O_{2}}}{R T}\right) \\
r_{2}=k_{2}[N O]^{2}\left[O_{2}\right]^{*} C_{\text {space }} \\
k_{2}=\frac{2 k_{B} T}{h} \exp \left(-\left(\frac{\Delta G_{T S 1(Z)}-2 \Delta G_{N O}-\Delta G_{O_{2}}}{R T}\right)\right)
\end{gathered}
$$

470 Where $r_{1}$ and $r_{2}$ are the corresponding reaction rates in the absence or presence of the zeolite 471 catalyst, respectively, $k_{B}$ is Boltzmann's constant, $h$ is Planck's constant, $T$ is the reaction 472 temperature, and $R$ is the ideal gas law constant. $\Delta G_{T S 1(Z)}, \Delta G_{N O}$ and $\Delta G_{O_{2}}$ represent the 
473 Gibbs free energy of the TS confined in zeolites, NO reactant, and $\mathrm{O}_{2}$ reactant, respectively;

$474 \Delta G_{T S 1}$ represents the Gibbs free energy of TS in uncatalyzed scenarios. $C_{\text {space }}$ is the number of 475 active, catalytic sites per unit mass of zeolite.

476 Differences in reaction rates for the two routes are attributed to $C_{\text {space }}$ and $\Delta G_{T S 1(Z)}$. 477 Likewise, the rate constants for the two scenarios differ due to variability in TS1's Gibbs free 478 energy. Steady-state NO conversion decreases with decreasing micropore volume (Figure 4).

479 This is consistent with the Eqs. (5-6). While $\mathrm{C}_{\text {space }}$ is dependent on effective pore volume or 480 availability of effective void space for $\mathrm{NO}$ oxidation, $\Delta G_{T S 1(Z)}$ is dependent on the 481 dimensional size of the void space relative to the size of TS1.

482 It is important to quantify the activation energy for these pathways, in addition to qualifying 483 the impact of the catalyst's physical structure. Born-Haber thermochemical cycles [54] 484 separate activation energy into enthalpy differences that independently reflect the properties of 485 the reactants and catalysts, allowing isolation of the role of zeolite pore structure on NO 486 reaction rates.

487 As previously mentioned, Figure 6 shows two hypothetical pathways (solid red arrows) to approach a confined TS1, based on Born-Haber thermochemical cycles. The first approach (uncatalyzed) begins with TS1 generation in the bulk gas phase followed by transport to and adsorption in zeolite void spaces. The second approach (catalyzed) generates TS1 directly in the void space, where it is confined. $E_{a u t o}$ (uncatalyzed) and $E_{w / c}$ (catalyzed) describe the activation energies of the two pathways, respectively:

$$
E_{\text {auto }}+\Delta_{r} H_{\mathrm{mads}}=E_{\mathrm{w} / \mathrm{c}}
$$


494 Because adsorption of TS1 is exothermic $\left(\Delta_{r} H_{\mathrm{mads}}<0\right)$, the catalyzed process has a lower 495 activation energy by $\left|\Delta_{r} H_{\mathrm{mads}}\right|$.

496

497

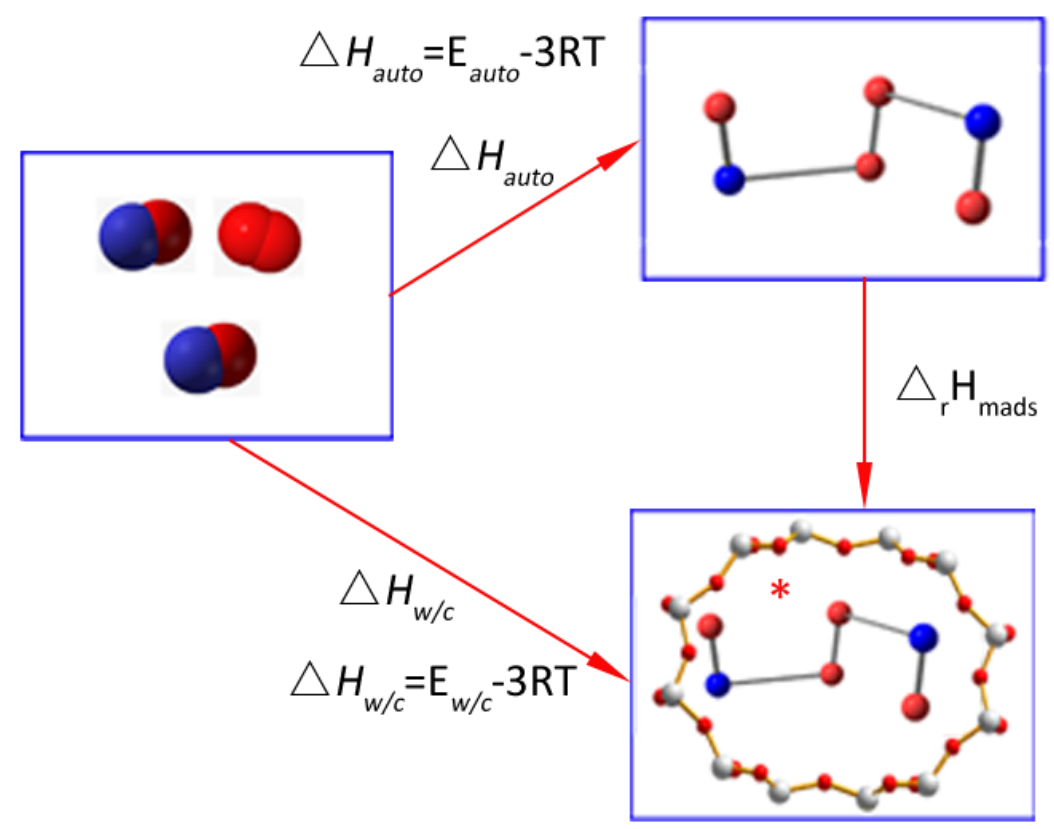

498

499 Figure 6 Thermochemcial cycle for NO oxiation catalyzed with zeolites via [ONOONO]

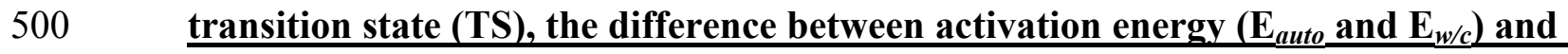

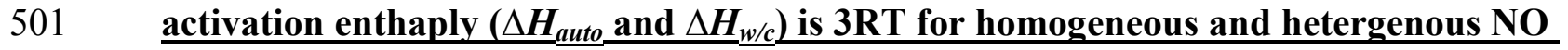
oxidation respectively, and 3 is introduced because 3 is the number of molecules involoved in the formation of TS. Activation energy $\left(E_{w / c}\right)$ depends on adsorption enthaplies $\left(\Delta_{r} \underline{H}_{\text {mads }}\right)$ of TS in void space and the intrinsic activation energy (E $\left.\underline{E}_{\text {auto }}\right)$ of NO 
507 Derouane et al. concluded that adsorption enthalpy $\left(\left|\Delta_{r} H_{m}\right|\right)$ is proportional to the van der

508 Waals interaction $\left(W_{r}(s)\right)$ of reactants and the zeolite's walls within void spaces [58]. The 509 adsorption enthalpy can be expressed as:

510

$$
\left|\Delta_{r} H_{m}\right|=\alpha W_{r}(s)=\alpha W(s) / W(0)=\alpha\left(1-1 / 2 *\left(d_{m o l}\right) /\left(d_{z e o}\right)\right)^{-3}
$$

511

$$
E_{\mathrm{w} / \mathrm{c}}=E_{\text {auto }}-\mid \Delta_{r} H_{\mathrm{m} \text { ads }} \mathrm{I}=E_{\text {auto }}-\alpha W_{r}(s)=\mathrm{E}_{\text {auto }}-\alpha W(s) / W(0)=\mathrm{E}_{\text {auto }}-\alpha\left(1-1 / 2 *\left(d_{\text {mol }}\right) /\left(d_{\text {zeo }}\right)\right)^{-3}
$$

514 Where $\alpha$ is constant, $d_{m o l}$ is the diameter of TS1, and $d_{z e o}$ is the diameter of the considered

515 void space. For results presented in this paper, activation energy is different for each zeolite

516 because of variability in $d_{z e o}$, which also causes variability in reaction rates according to

517 Arrhenius's Law [57]. Zeolites such as 13X, NaY, and MCM-41 show lower conversion due to

518 larger $d_{z e o}$. Zeolites with $d_{z e o}$ close to $d_{m o l}$, such as SAPO-34, MCM-22, MOR, ZSM-5, $\beta$, and

519 ZSM-22, yield higher conversion due to lower (more negative) activation energy.

520 Combining Eq. 5, Eq. 6, Eq. 9, and Gibbs free energy equation allows for determination of

521 reaction rate constants as a function of zeolite void space properties:

522

523

$r_{2}=\frac{2 k_{B} T}{h} \mathrm{e}^{3} \exp \left(\frac{\Delta S_{\text {auto }}+\Delta S_{\mathrm{m} \text { ads }}}{R}\right) \exp \left(-\frac{E_{\text {auto }}}{R T}\right) \exp \left(\frac{\alpha\left(1-1 / 2 *\left(\mathrm{~d}_{\text {mol }}\right) /\left(\mathrm{d}_{z e o}\right)\right)^{-3}}{R T}\right)[N O]^{2}\left[O_{2}\right]^{*} C_{\text {space }}$

525 Where $\Delta S_{\text {auto }}$ is the entropy of Route (1), and $\Delta S_{\text {mads }}$ is the entropy of TS adsorption in void space (Figure 5). 
formation for TS $\left(-31\right.$ to $\left.-41.2 \mathrm{~kJ} \mathrm{~mol}^{-1}\right)$, and negative entropies of formation (-262.3 to

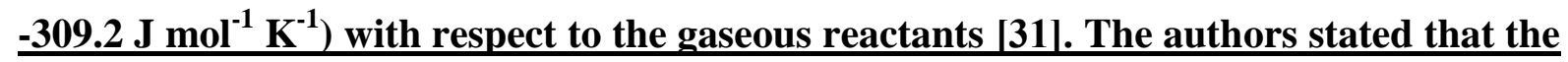

contribution of these entropy losses to the decrease of Gibbs free energy, along with

$r_{2}=\frac{2 k_{B} T}{h} \mathrm{e}^{3} \exp \left(\frac{-E_{\text {auto }}}{R T}\right)[N O]^{2}\left[O_{2}\right] \sum_{i=1}^{n} \exp \left(\frac{\Delta S_{\text {auto }}+\Delta S_{\text {mads }}^{i}}{R}\right) \exp \left(\frac{\alpha\left(1-1 / 2 *\left(\mathrm{~d}_{\text {mol }}\right) /\left(\mathrm{d}_{z e o}^{i}\right)\right)^{-3}}{R T}\right) * C_{\text {space }}^{i}$

Where $\mathrm{i}=1 \sim \mathrm{n}$, and $\mathrm{n}$ is the total number of pore width type available in zeolites. including: 1) increased conversion with increasing $[\mathrm{NO}]$ or $\left.\left[\mathrm{O}_{2}\right], 2\right)$ negative activation energy, catalyzed by microporous materials (including activated carbons and zeolites). Note that Eq.

11 is derived based only on the forward reaction rate and does not consider reverse reactions or the influence of $\mathrm{NO}_{2}$ inhibition. Kinetic studies with quantitative analyses to estimate thermodynamic values should be completed in future NO oxidation studies, 
549 It is challenging to test all 206 zeolite framework structures to determine those with high conversion. Instead, results presented here allow us to minimize the number of experiments by focusing only on zeolites that are predicted to perform well. Zeolites with high conversion should: 1) have channels $\geq 3.46 \AA$ that accommodate all reactants $\left(\mathrm{NO}\right.$ and $\left.\mathrm{O}_{2}\right)$ and products $\left(\mathrm{NO}_{2}\right), 2$ ) have void spaces (channels or cages) $\geq 4.67 \AA$ that accommodate TS1, 3) have void spaces $\leq 6.94 \AA$ that accommodate largest length scale for TS, maximizes van der Waals interaction between TS and the pore walls of the zeolite, and minimizes activation energy, and 4) if the cage size is $<6.94 \AA$, have channels not $<4.67 \AA$. These two boundaries $(4.67 \AA$ and $6.94 \AA$ ) are derived from TS calculations and summarized in Table 4. pore width for carbon, and recommended size for NO oxidation

\begin{tabular}{ll}
\hline Items & Scale $(\AA)$ \\
\hline Reactants & $\mathrm{NO}: 3.17, \mathrm{O}_{2}: 3.46$ \\
Products & $\mathrm{NO}_{2}: 3.40$ \\
Dimensional size of transition state & $6.94 \times 4.67 \times 4.46$ \\
Maximum free sphere diameter $\left(D_{\max }\right)$ & $4.70<D_{\max }<6.45$ \\
Maximum included sphere diameter $\left(D_{i}\right)$ & $5.71<D_{i}<7.37$ \\
Appropriate pore width for activated carbon fibers & 7 \\
Recommended size for NO oxidation & $4.67-6.94$ \\
\hline
\end{tabular}

561 Adhering to these criteria, zeolite structures that will be effective NO oxidation catalysts were predicted (Figure 7 and Table 5). Zeolites with potentially high NO conversion are 
concentrated between two horizontal lines $\left(D_{i}=4.67\right.$ and $\left.D_{i}=6.94\right)$. This analysis decreases

564 the number of possible zeolites that should be tested as NO oxidation catalysts from 206

565 codes to 82 codes. This screening from International Zeolite Association (IZA) database

566 is based on $D_{i}$ and $\underline{D}_{\max }$ and later achieved based on the accessibility of void space and

567 diffusion. In the future, more comprehensive/precise descriptors should be developed

568 that represent the size and volume of combined void spaces (not exclusively windows or

569 cavities). While the reliance on $D_{i}$ or $D_{\max }$ rationalizes most of the experimental results

570 described in this study, improvements could be made by using a more generic term to

571 describe the dominant properties and abundance to cause NO oxidation. Other

572 investigators are developing methods to determine such parameters [53, 59], and these

573 studies will be instrumental in identifying a more comprehensive/precise method to

574 predict NO conversion achieved by zeolite catalysts.

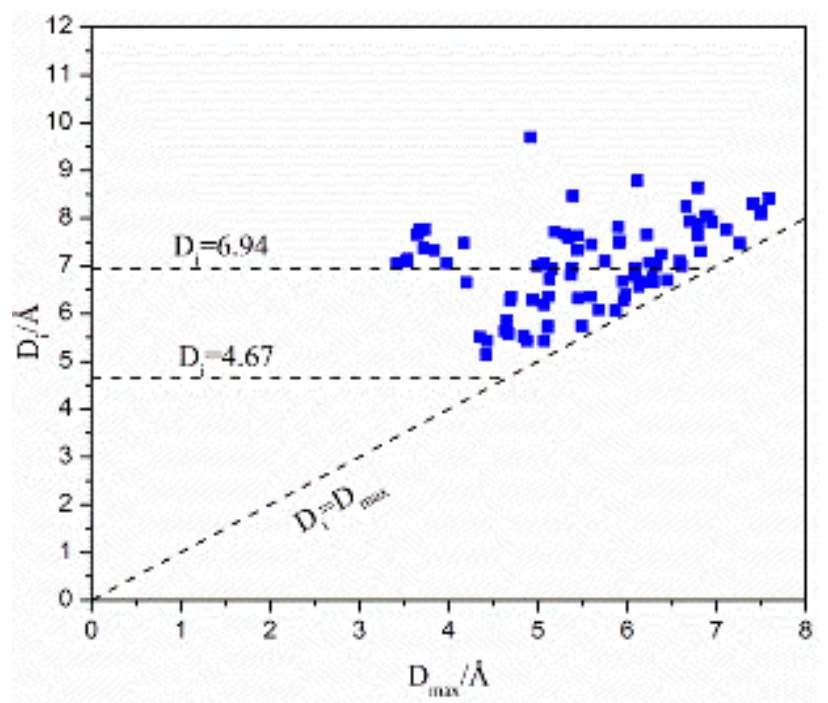

Figure 7 Preferred zeolites for NO oxidation from International Zeolite Association 
Table 5 Select zeolites for NO oxidation from International Zeolite Association [32]

\begin{tabular}{|c|c|c|c|c|c|c|c|c|c|c|c|c|c|}
\hline Code & AEI & AEL & AWW & $* \mathrm{BEA}$ & AFO & AFT & AFX & AFY & ASV & STI & *STO & STW & -SVR \\
\hline$D_{i} / \AA$ & 7.33 & 5.64 & 7.48 & 6.68 & 5.43 & 7.75 & 7.76 & 7.82 & 5.43 & 6.29 & 6.8 & 5.43 & 5.85 \\
\hline$D_{\max } / \AA$ & 3.84 & 4.63 & 4.17 & 5.95 & 5.07 & 3.68 & 3.73 & 5.9 & 4.43 & 4.94 & 6.09 & 4.88 & 4.65 \\
\hline Code & ATO & ATS & DDR & EAB & BEC & $\mathrm{BOF}$ & BOG & CAN & CFI & SZR & TER & TON & TUN \\
\hline$D_{i} / \AA$ & 5.74 & 7.30 & 7.66 & 7.14 & 6.95 & 5.58 & 8.05 & 6.27 & 7.47 & 6.27 & 6.94 & 5.71 & 8.46 \\
\hline$D_{\max } / \AA$ & 5.49 & 6.82 & 3.65 & 3.54 & 6.09 & 4.67 & 6.88 & 5.96 & 7.26 & 4.69 & 5.16 & 5.11 & 5.39 \\
\hline Code & CHA & $\mathrm{CON}$ & IFR & IMF & EON & ERI & EUO & EZT & FER & USI & UWY & VET & -WEN \\
\hline$D_{i} / \AA \AA$ & 7.37 & 7.45 & 7.24 & 7.34 & 7.87 & 7.04 & 7 & 6.57 & 6.31 & 6.76 & 8.78 & 6.39 & 5.53 \\
\hline$D_{\max } / \AA$ & 3.72 & 5.6 & 6.38 & 5.44 & 6.79 & 3.42 & 4.99 & 6.13 & 4.69 & 6.28 & 6.11 & 5.98 & 4.84 \\
\hline Code & GME & GON & LTF & MAZ & ISV & ITH & ITR & IWR & IWS & SFE & SFF & SFG & SFH \\
\hline$D_{i} / \AA$ & 7.76 & 6.32 & 8.16 & 8.09 & 7.01 & 6.72 & 6.36 & 7.48 & 8.25 & 6.66 & 7.59 & 6.96 & 7.63 \\
\hline$D_{\max } / \AA$ & 7.11 & 5.45 & 7.5 & 7.5 & 6.32 & 5.13 & 5.12 & 5.91 & 6.66 & 6.29 & 5.34 & 5.38 & 6.79 \\
\hline Code & IWW & LEV & MSE & MTT & MEI & MEL & MER & MFI & MFS & SFN & SFO & SFS & $* \mathrm{SFV}$ \\
\hline$\overline{D_{i} / \AA}$ & 7.07 & 7.1 & 7.09 & 6.19 & 8.06 & 7.72 & 6.65 & 6.36 & 6.81 & 7.94 & 7.92 & 7.52 & 7.67 \\
\hline$D_{\max } / \AA$ & 6.25 & 3.53 & 6.59 & 5.07 & 6.9 & 5.19 & 4.2 & 4.7 & 5.37 & 6.7 & 6.95 & 5.92 & 5.3 \\
\hline Code & MOR & MRE & PUN & $-\mathrm{RON}$ & MTW & MWW & NES & OFF & RTE & STF & SOF & SSF & SSY \\
\hline$D_{i} / \AA$ & 6.7 & 6.36 & 5.51 & 5.74 & 6.08 & 9.69 & 7.04 & 7 & 7.06 & 7.63 & 5.14 & 7.66 & 7.1 \\
\hline$D_{\max } / \AA$ & 6.45 & 5.59 & 4.35 & 5.11 & 5.68 & 4.92 & 5.07 & 6.61 & 3.98 & 5.44 & 4.42 & 6.22 & 5.75 \\
\hline Code & OSI & OSO & SAF & SAO & & & & & & & & & \\
\hline$D_{i} / \AA$ & 6.66 & 6.07 & 6.66 & 8.64 & & & & & & & & & \\
\hline$D_{\max } / \AA$ & 6.28 & 5.87 & 6.19 & 6.79 & & & & & & & & & \\
\hline
\end{tabular}




\section{Summary and Conclusions}

581 Experimental screening shows that zeolite-catalyzed steady-state NO conversion is not

582 strongly related to the catalyst's chemical composition, including surface hydroxyl groups 583 and Si/Al ratio, but strongly depends on the catalysts' void space dimensions and 584 concentrations. Chemical properties are shown to impact transient oxidation kinetics before 585 approaching stable NO concentration, which is consistent with previous studies describing 586 carbonaceous NO oxidation catalysts. A zeolite-catalyzed NO oxidation mechanism is proposed, based on both experimental results and quantum mechanical studies, which better accounts for trends that had previously not been justified in the literature. In

589 particular, the mechanism describes the impact of void space dimensions and volumes. The

590 mechanism provides a pathway where transition state 1 (TS1) is generated and confined in

591 void spaces. Lowest activation energy and high reaction rates, influenced by the dimensions

592 of void spaces, are achieved in the effective void space with dimensions ranging between

5934.67 and $6.94 \AA$, consistent with reported results for activated carbon fibers. The mechanisms

594 for activated carbon fiber cloth and zeolites confirm that steady-state NO conversion is

595 mainly dependent on the catalyst's physical properties. Engineering materials with

596 appropriate pore width and large micropore volume in the range of appropriate pore width

597 presumably renders high conversion of NO oxidation. This provides the background needed

598 to more effectively investigate select zeolites and carbons as NO oxidation catalysts, as well

599 as other unique materials that have not yet been considered for these reactions (e.g., metal 600 organic frameworks). 
602 Funding was provided by the United States' National Science Foundation (NSF A1918 and

603 NSF CBET 10-34470), and Zhejiang Provincial Natural Science Foundation of China

604 (LY14E080001). Support for Z. Zhang was provided by Chinese Scholarship Council

605 (2011645015). X-ray diffraction was carried out in the Frederick Seitz Materials Research

606 Laboratory Central Facilities, University of Illinois, which are partially supported by the U.S.

607 Department of Energy under grants DE-FG02-07ER46453 and DE-FG02-07ER46471. Zeolyst,

608 Nanki Catalyst Company, and Jiangge Hao of Tianjin University are acknowledged for

609 providing the tested zeolites. Jinyang $\mathrm{Xi}$ of Tsinghua University is acknowledged for

610 calculating the transition state volume, and Dr. Phillip H. Geil of UIUC is acknowledged for

611 providing the hydraulic press used for catalyst preparation.

\section{References}

613 [1] G. Qi, R.T. Yang, R. Chang, Appl. Catal. B 51 (2004) 93-106.

614 [2] Z. Zeng, P. Lu, C. Li, L. Mai, Z. Li, Y. Zhang, Catal. Sci. Technol. 2 (2012) 2188-2199.

615 [3] Q.P. Wu, G. Mul, R. van de Krol, Energy Environ. Sci. 4 (2011) 2140-2144.

616 [4] Envrionmental Protection Ministry PRC, Waste gas, Ministry of Environmental Protection, PRC,

617 Retrieved May 12 ${ }^{\text {th }}$ 2013, from http://zls.mep.gov.cn/hjtj/nb/2010tjnb/201201/t20120118_222725.htm.

618 [5] State Council, Energy Conservation and Emissions Reduction in $12^{\text {th }}$ Five Year Plan, China New Energy

619 Website, Retrieved May 12 $2^{\text {th }}$ 2013, from http://www.china-nengyuan.com/news/37608.html.

620 [6] S. Brandenberger, O. Kröcher, A. Tissler, R. Althoff, Catal. Rev. 50 (2008) 492-531.

621 [7] M. Shelef, Chem. Rev. (Washington, DC, U. S.) 95 (1995) 209-225. 
[8] W.J. Zhang, S. Rabiei, A. Bagreev, M.S. Zhuang, F. Rasouli, Appl. Catal. B 83 (2008) 63-71.

[9] J.F. Brilhac, A. Sultana, P. Gilot, Martens, Environ. Sci. Technol. 36 (2002) 1136-1140.

624

[10] X. Chang, G. Lu, Y. Guo, Y. Wang, Y. Guo, Micro. Meso. Mater. 165 (2013) 113-120.

625

[11] S. Liu, Fundamental research on removal of $\mathrm{SO}_{2}$ over activated carbon and metal doped carbon, Zhejiang

University Zhejiang, 2011.

627

[12] J.D. Atkinson, Z.Q. Zhang, Z.F. Yan, M.J. Rood, Carbon 54 (2013) 444-453.

628

[13] I. Mochida, Y. Kawabuchi, S. Kawano, Y. Matsumura, M. Yoshikawa, Fuel 76 (1997) 543-548.

629

[14] I. Mochida, S. Kisamori, M. Hironaka, S. Kawano, Y. Matsumura, M. Yoshikawa, Energy Fuels 8 (1994)

630 $1341-1344$.

631

[15] I. Mochida, N. Shirahama, S. Kawano, Y. Korai, A. Yasutake, M. Tanoura, S. Fujii, M. Yoshikawa, Fuel 79

632

(2000) 1713-1723.

633

[16] J.P.S. Sousa, M.F.R. Pereira, J.L. Figueiredo, Catal. Today 176 (2011) 383-387.

634

[17] J.P.S. Sousa, M.F.R. Pereira, J.L. Figueiredo, Appl. Catal. B 125 (2012) 398-408.

635

[18] S. Sumathi, S. Bhatia, K.T. Lee, A.R. Mohamed, Chem. Eng. J. (Lausanne) 162 (2010) 51-57.

636

[19] S. Sumathi, S. Bhatia, K.T. Lee, A.R. Mohamed, J. Hazard. Mater. 176 (2010) 1093-1096.

637 [20] Y.F. Li, H.Y. Liu, H.F. Huang, H.F. Lu, Y.F. Chen, Chin. Environ. Sci. 30 (2010) 161-166.

638 [21] Y.F. Li, H.Y. Liu, H.F. Huang, Z.K. Zhang, Y.F. Chen, Chin. Environ. Sci. 29 (2009) 469-473.

639 [22] H. Liu, Z. Zhang, Y. Xu, Y. Chen, X. Li, Chin. J. Catal. 31 (2010) 1233-1241.

640 [23] H.Y. Liu, Y.F. Li, Y.Y. Xu, Y.F. Chen, X. Li, J. Chem. Eng. Chin. Univ. 25 (2011) 615-621.

641 [24] Na Xing, Xinping Wang, Qing Yu, X. Guo, Chin. J. Catal. 28 (2007) 205-209.

642 [25] J. Despres, M. Koebel, O. Kröcher, M. Elsener, A. Wokaun, Micro. Meso. Mater. 58 (2003) 175-183. 
643 [26] Y. Wang, Z. Lei, B. Chen, Q. Guo, N. Liu, Appl. Surf. Sci. 256 (2010) 4042-4047.

644 [27] D.J. Kang, X. Tang, J. Peng, H. Yi, P. Ni, Ye Zhiqing, K. Li, Adv. Mater. Res. 383-390 (2011) 3056-3062.

645 [28] S.E. Schwartz, W.H. White, Solubility equilibria of the nitrogen oxides and oxyacids in dilute aqueous 646 solution Gordon and Breach Science Publishers, New York, NY, 1981.

647 [29] J.H. Seinfeld, Atmospheric Chemistry and Physics of Air Pollution, Wiley-Interscience, New York, 1986.

648 [30] P. Nowicki, R. Pietrzak, Chem. Eng. J. (Lausanne) 166 (2011) 1039-1043.

649 [31] N. Artioli, R.F. Lobo, E. Iglesia, J. Phys. Chem. C 117 (2013) 20666-20674.

650 [32] M. Richter, R. Eckelt, B. Parlitz, R. Fricke, Appl. Catal. B 15 (1998) 129-146.

651 [33] I. Halasz, A. Brenner, K.Y. Simon Ng, Catal. Lett. 34 (1995) 151-161.

652 [34] J.A. Loiland, R.F. Lobo, J. Catal. 311 (2014) 412-423.

653 [35] Ch. Baerlocher and L.B. McCusker, Database of Zeolite Structures: http://www.iza-structure.org/databases/ 654 [36] M.D. Foster, M.M.J. Treacy, A database of hypothetical zeolite structures, 655 http://www.hypotheticalzeolites.net.

656 [37] Z. Zhang, J.D. Atkinson, B. Jiang, M.J. Rood, Z. Yan, Appl. Catal. B 148-149 (2014) 573-581.

657 [38] J. D. Atkinson, Z. Zhang, M. J. Rood, Impact of Carbon's Porosity and Surface Chemistry on NO oxidation 658 Efficiency, $105^{\text {th }}$ Air \& Waste Management Association Conference, San Antonio, 2012, pp. Paper 659 2012-A-2058-AWMA.

660 [39] O.B. Gadzhiev, S.K. Ignatov, S. Gangopadhyay, A.m.E. Masunov, A.I. Petrov, J. Chem. Theory Comput. 7 $661 \quad$ (2011) 2021-2024.

662 [40] Q. Zhang, C. Li, H. Shan, C. Yang, Chem. J. Chin. Univ. 32 (2011) 2721-2726.

663 [41] C.-M. Song, J. Jiang, Z.-f. Yan, J. Porous Mater. 15 (2008) 205-211. 
[43] Test Method for Determination of Relative Crystallinity of Zeolite ZSM-5 by X-Ray Diffraction, ASTM

667 International, 2001.

668

[44] M.M.J. Treacy, M.D. Foster, Micro. Meso. Mater. 118 (2009) 106-114.

[45] G.W.T. M. J. Frisch, H. B. Schlegel, G. E. Scuseria, M. A. Robb, J. R. Cheeseman, G. Scalmani, V. Barone,

B. Mennucci, G. A. Petersson, H. Nakatsuji, M. Caricato, X. Li, H. P. Hratchian, A. F. Izmaylov, J. Bloino, G.

679 [46] S.S. Batsanov, Inorg. Mater. 37 (2001) 871-885.

680 [47] N. Tang, Y. Liu, H. Wang, Z. Wu, J. Phys. Chem. C 115 (2011) 8214-8220.

681 [48] Y. Yang, N. Burke, J. Zhang, S. Huang, S. Lim, Y. Zhu, RSC Adv. 4 (2014) 7279-7287.

682 [49] Z.-M. Wang, T. Arai, M. Kumagai, Energy Fuels 12 (1998) 1055-1060.

683 [50] Z. Zhang, J.D. Atkinson, H. Song, M.J. Rood, Z. Yan, Structure Sensitivities of SAPO Zeolites on Catalytic 684 Oxidation of Nitric Oxide, $106^{\text {th }}$ Air\&Waste Management Association Chicago, 2013, p. pp12406. 
685 [51] S. Smeekens, S. Heylen, N. Janssens, K. Houthoofd, J.A. Martens, C.E.A. Kirschhock, Chem. Mater. 23

686 (2011) 4606-4611.

687 [52] A.M. Rubel, J.M. Stencel, Energy Fuels 10 (1996) 704-708.

688 [53] E.L. First, C.E. Gounaris, J. Wei, C.A. Floudas, Phys. Chem. Chem. Phys. 13 (2011) 17339-17358.

689 [54] R. Gounder, E. Iglesia, J. Am. Chem. Soc. 131 (2009) 1958-1971.

690 [55] R. Gounder, E. Iglesia, Chem. Commun. (Cambridge, U. K.) 49 (2013) 3491-3509.

691 [56] H. Tsukahara, T. Ishida, M. Mayumi, Nitric Oxide 3 (1999) 191-198.

692 [57] X. Fu, W. Shen, t. Yao, W. Hou, Handbook of Physical Chemistry, High Education Press, Beijing, 2005.

693 [58] E.G. Derouane, J.-M. Andre, A.A. Lucas, J. Catal. 110 (1988) 58-73.

694 [59] A.J. Jones, C. Ostrouchov, M. Haranczyk, E. Iglesia, Micro. Meso. Mater. 181 (2013) 208-216.

695

696 
698 Figure 1 Steady-state NO conversion over select zeolites at $25{ }^{\circ} \mathrm{C}$ and $50{ }^{\circ} \mathrm{C}$, SAPO-5 and

699 ZSM-5-c was not included because the test at $50{ }^{\circ} \mathrm{C}$ did not occur due to the insufficiency of

700 SAPO-5 and ZSM-5-c.

701 Figure 2 Relationship between steady-state NO conversion, adsorption capacity and $\mathrm{Si} / \mathrm{Al}$

702 molar ratio for select zeolites $\left(25^{\circ} \mathrm{C}\right)$.

703 Figure 3 Zeolite structure-NO conversion relationship versus: a) total and micropore surface

704 areas; b) total and micropore pore volumes; c) maximum free sphere diameter $\left(D_{\max }\right)$; and d)

705 maximum included sphere diameter $\left(D_{i}\right)$.

706 Figure 4 NO conversion as a function of a) relative crystallinity and micropore pore volume,

707 and b) mesopore pore volume of alkali-treated ZSM-5.

708 Figure 5 Proposed reaction mechanism for NO oxidation. Route (1) represents the

709 uncatalyzed oxidation pathway. Route (2) represents the pathway in the presence of zeolites.

710 The inset describes the 3D spatial configuration of transient state derived from simulation,

711 where red spheres represent oxygen and blue spheres represent nitrogen. The structures in

712 shaded box is the TS with length, width and height dimensions. $\Delta \mathrm{G}_{\text {meas }}$ and $\Delta \mathrm{G}_{\text {auto }}$ represent the

713 differences between reactants and either confined TS and unconfined TS. Confined TS,

714 marked with asterisk, indicates that the spatial configuration of TS is different from unconfined

715 TS in spite of the same geometries shown in this figure. 
716 Figure 6 Thermochemcial cycle for NO oxiation catalyzed with zeolites via [ONOONO] TS,

717 the difference between activation energy $\left(\mathrm{E}_{\text {auto }}\right.$ and $\left.\mathrm{E}_{w / c}\right)$ and activation enthaply $\left(\Delta H_{\text {auto }}\right.$ and

$\left.718 \Delta H_{w / c}\right)$ is $3 \mathrm{RT}$ for homogeneous and hetergenous NO oxidation, and 3 is introduced because 3

719 is the number of molecules involoved in the formation of TS. Activation energy $\left(\mathrm{E}_{w / c}\right)$

720 depends on adsorption enthaplies $\left(\Delta_{\mathrm{r}} \mathrm{H}_{\text {mads }}\right)$ of transitent state in void space and the intrinsic

721 activation energy $\left(\mathrm{E}_{\text {auto }}\right)$ of $\mathrm{NO}$ homogenous oxidation.

722 Figure 7 Preferred zeolites for NO oxidation from International Zeolite Association, squares

723 represent zeolites with the specified values for $D_{i}$ and $D_{\max }$. 


\section{Table Captions}

726 Table 1 Tested zeolites and carbon, their suppliers, and compositions

727 Table 2 Topological information and physical properties of select zeolites

728 Table 3 Micropore volume, NO conversion, and pseudo turnover frequency (Pseudo TOF)

729 values for zeolites and activated carbon fiber cloth (ACFC) and at $50{ }^{\circ} \mathrm{C}$

730 Table 4 The length scales of reactants, products, TS, $D_{\max }$ and $D_{i}$ for zeolites, pore width for

731 carbon, and recommended size for NO oxidation

732 Table 5 Select zeolites for NO oxidation from International Zeolite Association 


\section{Graphical Abstract for}

"NO Oxidation by Microporous Zeolites: Isolating the Impact of Pore Width to Predict Conversion" for possible publication in Applied Catalysis B:

\section{Environmental}

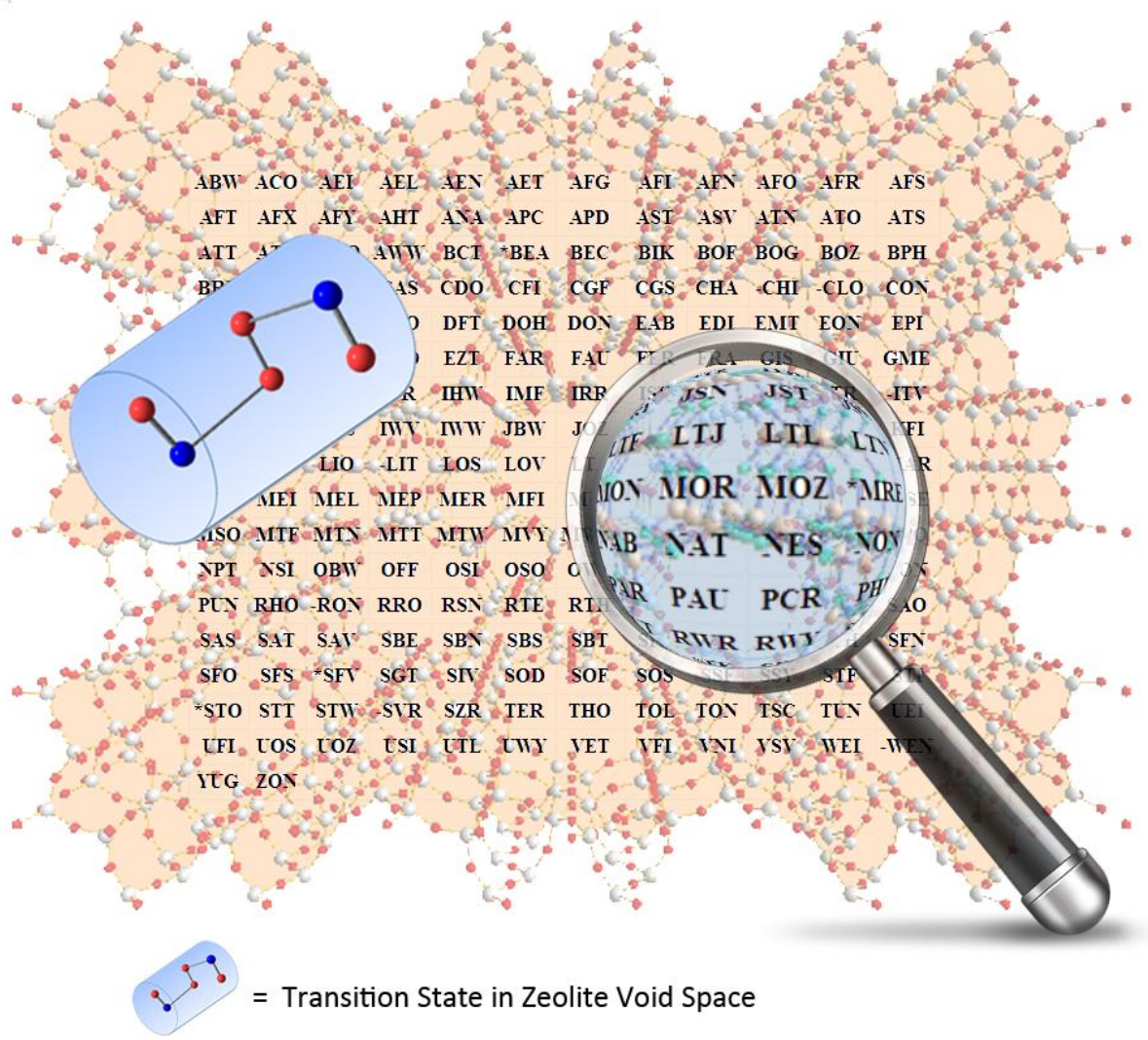

Screening Potential Zeolites for NO Oxidation Based on Transition State Confinement Mechanism 